\title{
Behavioral economics and
}

SFB

823

\section{energy conservation - a}

systematic review of non-

price interventions and their

causal effects

Mark Andor, Katja Fels

Nr. 14/2017

$\infty$

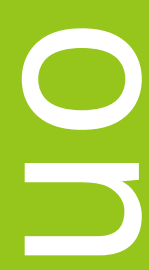

ע

(1)

(1)

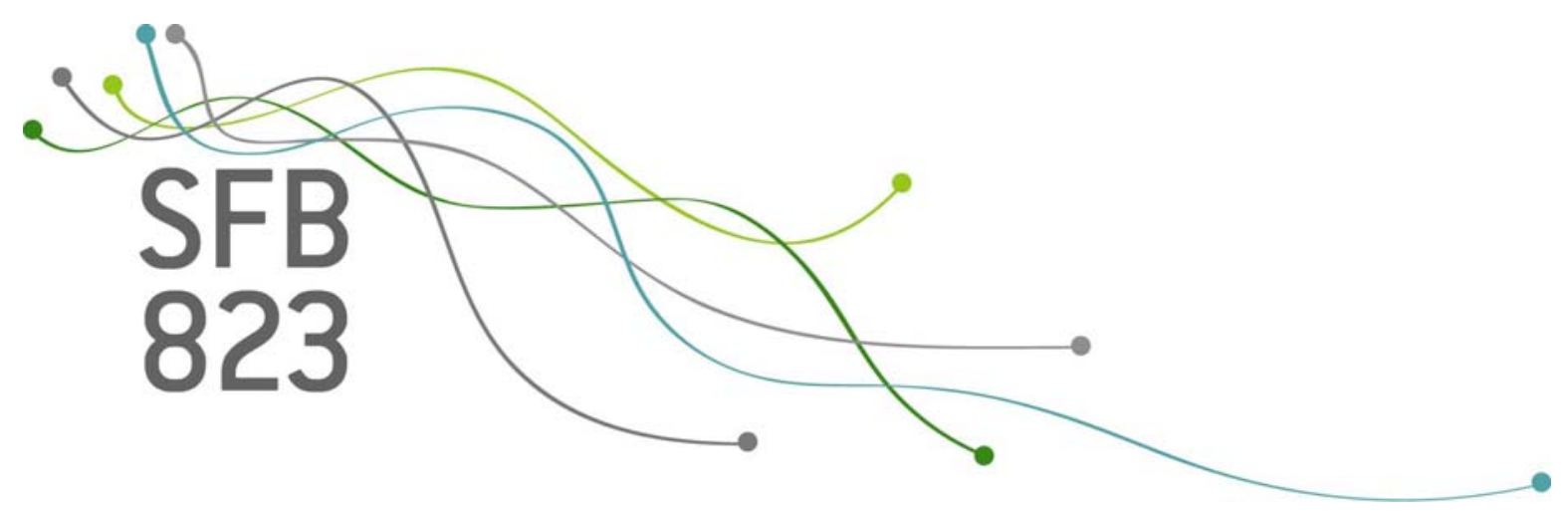





\title{
Behavioral Economics and Energy Conservation - A Systematic Review of Non-price Interventions and their Causal Effects
}

\author{
Mark Andor and Katja Fels
}

July 2017

\begin{abstract}
Research from economics and psychology suggests that behavioral interventions can be a powerful climate policy instrument. This paper provides a systematic review of the existing empirical evidence on non-price interventions targeting energy conservation behavior of private households. Specifically, we analyze the four nudge-like interventions referred to as social comparison, pre-commitment, goal setting and labeling in 38 international studies comprising 91 treatments. This paper differs from previous systematic reviews by solely focusing on studies that permit the identification of causal effects. We find that all four interventions have the potential to significantly reduce energy consumption of private households, yet effect sizes vary immensely. We conclude by emphasizing the importance of impact evaluations before rolling out behavioral policy interventions at scale.
\end{abstract}

\section{JEL Codes: D10, D12, L94, L95, Q41, Q48, Q58}

Keywords: Systematic review; Behavioral economics; Energy demand;

Energy efficiency; Environmental certification; Social norms

Correspondence: Mark Andor, RWI - Leibniz Institute for Economic Research, Hohenzollernstr. 1-3, D-45128 Essen. E-mail: andor@rwi-essen.de.

Acknowledgements: We are grateful for invaluable comments and suggestions by Gunther Bensch, Jörg Langbein, Jörg Peters, Christoph M. Schmidt, and Colin Vance. We also thank Marvin Gleue, Nadine Kneppel, Marc Teipel and Maximilian Zettler for excellent research assistance. We gratefully acknowledge financial support by the National Academy of Science and Engeneering (acatech). Furthermore, this work has been partly supported by the Collaborative Research Center "Statistical Modeling of Nonlinear Dynamic Processes" (SFB 823) of the German Research Foundation (DFG), within Project A3, "Dynamic Technology Modeling". Fels gratefully acknowledges the support of a special grant (Sondertatbestand) from the German Federal Ministry for Economic Affairs and Energy and the Ministry of Innovation, Science, and Research of the State of North Rhine-Westphalia. 


\section{Introduction}

Climate change mitigation programs are on the political agenda worldwide. As a result of ambitious CO2-reduction goals, policymakers are increasingly interested in non-price interventions targeting private household energy consumption. Both economic and psychological research has shown that behavioral interventions - also referred to as nudges - can be powerful tools in shaping people's behavior in a variety of domains (see, among others, the influential publication by Thaler and Sunstein 2008). ${ }^{1}$ Non-price measures are relatively inexpensive to implement and do not interfere with people's choice sets as strongly as, for example, taxes or bans on certain products. Consequently, policy makers are now exploring nudges as a cost-effective approach for reducing energy consumption (Allcott 2015). If proven effective, these interventions could be established as an integral and complementary component of climate change policy (Allcott and Mullainathan 2010). This is why researchers are increasingly interested in understanding the effect of nonprice measures on residential energy consumption.

This paper presents findings of a systematic review of the effectiveness of behavioral interventions to induce energy conservation. We study the following four interventions: social norms, commitment devices, goal setting, and labeling. Furthermore, the review focuses on "higher quality" studies. To this end, we only include those studies that employ an empirical estimation strategy enabling the identification of a causal relationship between a policy intervention and consumption behavior. To our knowledge, it is the first study that systematically reviews all published results from behavioral economics and related areas of research that are based on a rigorous evaluation of causal effects.

\footnotetext{
${ }^{1}$ The fact that the book Nudge (Thaler and Sunstein 2008) has already been cited more than 7,000 times can be seen as one indicator of a growing academic interest in behavioral interventions (cf. Allcott and Kessler 2015).
} 
Our study builds on a few earlier reviews that only focus on a subset of our interventions. Many of these point to potential problems of including effects from correlational studies in their sample, i.e. studies that are not able to disentangle causation from correlation. Abrahamse et al. (2005) evaluate the effectiveness of some interventions aiming to encourage households to reduce energy consumption. They conclude that information has an influence on knowledge, but does not necessarily result in behavioral changes or energy savings. Rewards have effects on energy conservation, but they are rather short-lived. Feedback, in particular when it is given frequently, can also be effective. More recently, Karlin et al. (2015) conducted a meta-analysis on the effect of feedback on energy usage. They conclude that feedback is effective but with significant variation in effects. Furthermore, Delmas et al. (2013) analyze the effect of information strategies on energy savings and find a substantial reduction effect on average. However, in a similar vein as Abrahamse et al. (2005), they conclude that the effect diminishes with the rigor of the study, indicating potential methodological issues in the considered literature. In particular, none of the existing reviews takes into account whether the considered studies apply a method that has the potential to identify the causal effect of the intervention, which is critical to the question of its policy relevance (Imbens and Wooldridge 2009).

Consequently, our systematic review differs from previous research by solely focusing on studies that have the potential to identify causal effects between the intervention and the outcome. Furthermore, we include articles published up to December 2015 in working paper series as well as peerreviewed journals to provide the most comprehensive and up-to-date account of research in economics and psychology. This is particularly important because there has been a growing number of high-quality studies in the recent past. Hence, our review comprises several very recent large-scale randomized controlled field experiments. As an additional contribution, our systematic 
review is the first to account for labeling as a non-price intervention, which has been applied worldwide on a large scale and potentially affects millions of household decisions each year.

The paper proceeds as follows. In the subsequent section, we define and motivate the four considered interventions. Section 3 explains the methodology of the systematic review. In Section 4, we synthesize and discuss the results. Section 5 concludes with recommendations for researchers and policy makers.

\section{Behavioral interventions and energy conservation}

A considerable percentage of annual emissions in industrial countries is induced by residential energy consumption. In addition, private households are a prime target for behavioral interventions (Karlin et al. 2015). Households may conserve energy in two ways: First, they can change their consumption of energy services, for example by reducing lighting use. Second, they can modify their purchasing behavior and invest in energy efficiency, for example by buying a highly efficient washing machine. ${ }^{2}$ Behavioral interventions with the aim of inducing energy conservation can therefore target either the purchase decision or more directly the consumption behavior. Below we examine the four non-price interventions considered in our systematic review and their potential effects on energy-conservation behavior of private households.

\footnotetext{
${ }^{2}$ The purchase of an energy efficient appliance will ultimately result in reduced energy consumption when expected energy savings are not completely offset by an increase in the use of the appliance, which is known as the rebound effect (see, for instance, Frondel and Vance 2013).
} 


\section{Social comparison}

Social comparison refers to the process of giving households information about their energy consumption in relation to the consumption of comparable households. Such a comparison is closely connected to also receiving feedback about one's own behavior. The chosen reference group should be relevant for the treated household (Abrahamse et al. 2005) and can be, for instance, consumers of the same energy provider or households within the same postcode-level. Moreover, the choice of the reference level is important: the household's consumption can either be compared to the average consumption level of the reference group or to a more ambitious group, e.g. the most efficient 10 percent.

The potential effect of a social comparison might be triggered by three phenomena. First, many people exhibit reference dependent preferences (Kahneman 2003). Accordingly, one reference point is social norms. Complying with these norms increases most individuals' utility whereas deviating from it typically leads to disutility caused by social disapproval (Schubert and Stadelmann 2015). Second, in situations of uncertainty, individuals may use other peoples' behavior as orientation by implicitly assuming that those others have more information about the socially desired behavior (Allcott and Mullainathan 2010, see also Delmas et al. 2013). Consequently, people tend to adjust their actions according to the prevalent group behavior. Third, social comparisons evoke feelings of competition (Abrahamse et al. 2005). This is especially important when the household's consumption level lies above the average or above some threshold that the household perceives as desirable (for example, belonging to the most efficient 10 percent of costumers). 


\section{Commitment Devices}

Commitment devices are "a set of interventions that allow individuals to lock themselves today into the action that they want to take tomorrow" (Allcott and Mullainathan 2010: 2). Examples of commitment devices are oral or written pledges or promises to conserve energy (Abrahamse et al. 2005). The commitment can either be a promise to oneself, or alternatively it can be made public.

The idea behind voluntarily binding one's own future behavior is that some people are aware that they sometimes have time-inconsistent preferences (O'Donoghue and Rabin 1999). For instance, as O'Donoghue and Rabin (2008) point out, many people procrastinate sometimes to the extent that the desired action is never taken.

A commitment device helps individuals to overcome such timeinconsistent preferences by providing a source of motivation: it compares the present situation with a desired future state (van Hoewelingen and van Raaij 1989). When the commitment is a pledge to oneself, it appeals to a personal norm (the individual wants to satisfy expectations towards itself). A public commitment creates expectations by others, thereby leading to social pressure (Abrahamse et al. 2005).

\section{Goal Setting}

Goal setting combines commitment with a concrete reference point. Instead of pledging to conserve energy, a household specifically promises, for instance, "to reduce energy consumption by 10 percent within the next month". Not only setting a reduction level but also a deadline for achieving this goal facilitates an evaluation of success or failure. This increases pressure but also motivation by making satisfaction conditional on a desired level of performance (van Houwelingen and van Raaij 1989). A goal can be chosen by 
the household itself (being a form of commitment device) or externally set (for example by institutions).

The underlying mechanisms explaining the potential effects of goal setting are similar to those of commitment devices: time-inconsistent preferences and a lack of self-control. In addition to that, a specific goal targets reference-dependent preferences (Abrahamse et al. 2005): individuals aim at a pre-determined level and judge their performance according to this reference point. Achievement of the goal provides a feeling of accomplishment, whereas failure creates disutility even if the goal level was externally set (Bandura 1986).

\section{Labeling}

A label is a tag that summarizes information on a good in an easily accessible way. This can be achieved by presenting a selection of information about the product's attributes on the label or by visualizing the most relevant information in a graphical manner. In the domain of energy consumption, labels can, for example, comprise information on energy usage levels of appliances or energy efficiency standards of houses.

In principle, there are two different sorts of labels. Either the labeling program is voluntary and an appliance is awarded the label for satisfying certain criteria like the US Energy Star Label, or a label is mandatory for all appliances, as with the EU Energy Label. In the latter case, goods can be ranked according to their performance along the criteria specified by the label, for instance the EU energy efficiency classes.

Consumers potentially respond to labels by ascribing more attention to certain features of the good. As a label makes selected criteria (more) salient, it aims at the availability heuristic, i.e. a simplifying rule that gives highly accessible features a stronger influence on decisions while information of low 
accessibility will largely be ignored (Kahneman 2003). This remains true even when costs of gathering relevant information, for example on average usage levels or life expectancy of appliances, is low (Schubert and Stadelmann 2015).

\section{Methodology}

Following the guidelines for systematic reviews suggested by the Campbell Collaboration (2014), we take five successive steps to identify and analyze relevant studies: setting up criteria for including studies in the review, literature search, selection of studies, data extraction, and data analysis.

\subsection{Inclusion criteria (PICOS)}

As a first step, we developed a set of criteria along the so-called PICOS - an acronym for participants, interventions, comparisons, outcomes, and study designs (Campbell Collaboration 2014). The PICOS guided the selection of studies in the further process. We include studies targeting private households or individuals living in an industrialized or emerging country where the living situation (especially in regard to energy consumption) is comparable to an industrialized country. Studies focusing on energy consumption in official buildings or enterprise settings are excluded.

Our focus is on the four interventions social comparison, commitment devices, goal setting, and labeling. We also consider combinations of these interventions with each other or with additional non-price measures (e.g. feedback, energy savings tips). In contrast, all studies combining these interventions with financial incentives (for instance, dynamic pricing) are excluded from the review, as long as they do not allow to identify the effect of the non-price intervention separately.

Regarding the outcome, we include all studies that report an individual's or household's actual or self-assessed usage level of energy, gas, 
or water. For labeling, we also consider secondary outcomes like the perception of and the willingness to pay for energy efficiency. These secondary outcomes influence usage levels via different channels (as discussed in Section 2).

We include all studies that permit the identification of the causal relationship between the intervention and the outcome of interest. Hence, studies are considered if their methodology is based on a higher quality causal inference design like randomized controlled trials (RCT), matching, difference-in-differences, instrumental variable estimation, and regression discontinuity design, or if they control for self-selection with alternative methodologies. ${ }^{3}$ Studies that do not employ methods suitable for identifying the causal effect of an intervention are excluded from the review. Overall, we apply no time restriction: all study results published in a journal or as working paper up until the end of 2015 are considered in the review.

\subsection{Literature search}

We used two main avenues to identify relevant studies: First, a keyword search in databases, and second, a backward search on relevant review studies. Before the database search, we pre-determined a systematic combination of keywords for each of the four interventions (see Appendix B1). These keywords were employed on two databases: EconLit, consisting of more than 785,000 articles from peer-refereed journals and acknowledged working paper series in economics, and ScienceDirect, accessing more than 13 million articles from journals in different disciplines, from which our study chose the disciplines "Economics, Econometrics, Finance", "Psychology", "Social Sciences", "Environment", and "Energy". This returned a total of 988 results.

\footnotetext{
${ }^{3}$ For an excellent overview of high quality causal inference designs see Angrist and Pischke (2009) or Imbens and Wooldrigde (2009).
} 
Additionally, we conducted backward searches in the literature of the following four review studies: Abrahamse et al. (2005), Delmas et al. (2013), Karlin et al. (2015) and Lokhorst et al. (2013). Of the 147 articles identified, we included 71 studies after ruling out duplicates. This garnered a total of 1,059 studies for the screening process of this review (see Figure 1).

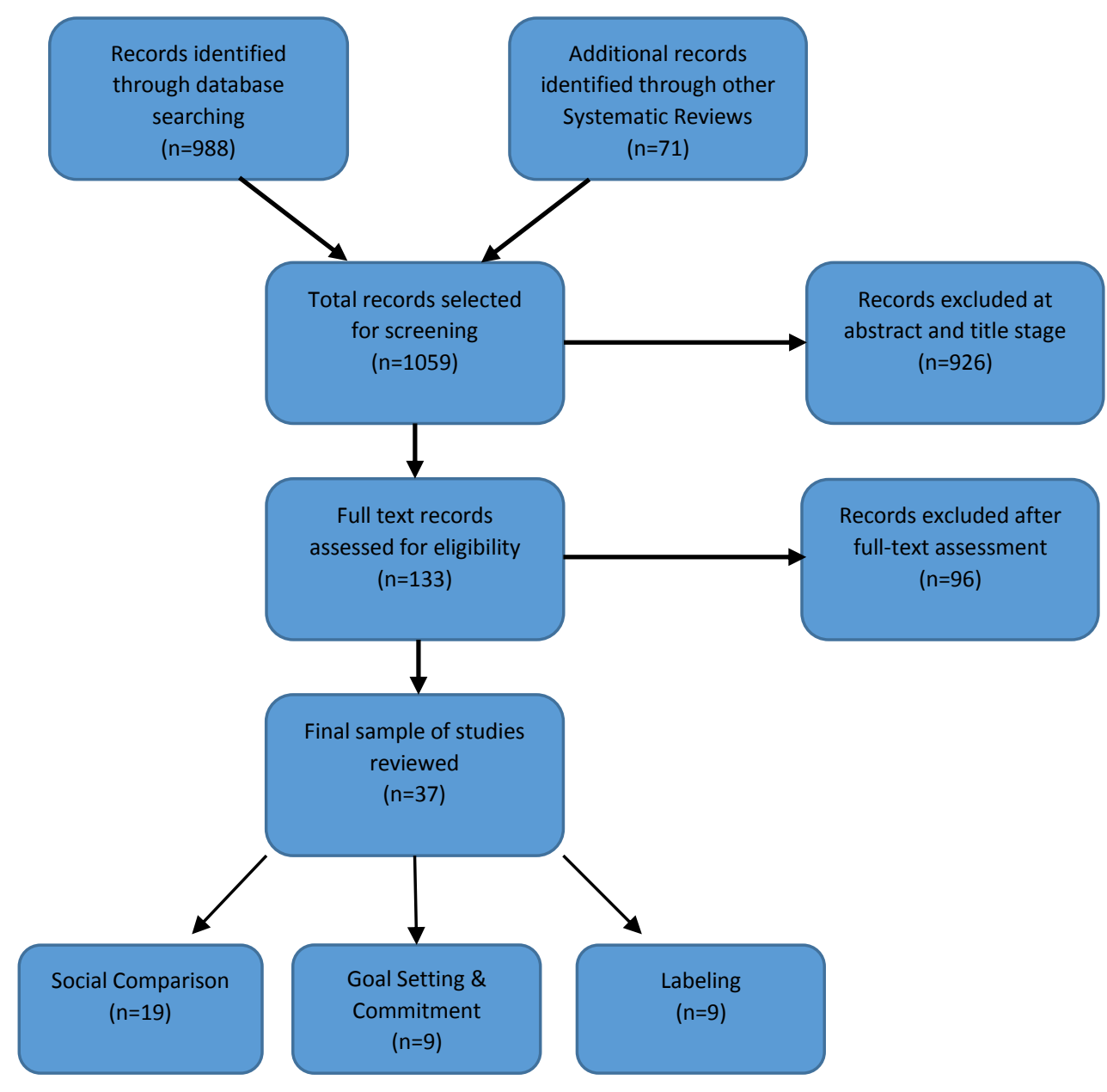

Figure 1: Overview of results in the searching, screening and selection process ${ }^{4}$

\footnotetext{
${ }^{4}$ The study by Kurz et al. (2005) investigates a social comparison treatment as well as labeling. Here it is categorized as a social comparison study.
} 


\subsection{Selection of studies}

All studies were screened by independently reading the title and abstract and assessing whether a study satisfied all inclusion criteria set up in the PICOS via an inclusion decision form (see Appendix B2). We excluded 926 studies due to this procedure, leaving 133 articles for full text screening (see Figure 1), which again was conducted independently. In cases of differing assessments, we consulted a third (independent) scientist and solved discrepancies by discussion. A common reason for exclusion was that studies discussed strategies for energy conservation behavior theoretically or approached it with a qualitative design without actually measuring the effect of an intervention. When screening the selected full text articles, the main reason for exclusion was that studies neither applied a higher quality causal inference design nor controlled for self-selection. In contrast, at the start of the screening process a majority of papers was completely off-topic. Finally, 37 articles satisfied the criteria of this systematic review.

\subsection{Data extraction}

We developed a detailed coding sheet (see Appendix B3) based on the guidelines of the Campbell Collaboration (2014). Two reviewers coded each study independently of each other according to the same criteria. In cases in which the extracted information was ambiguous (for instance regarding the method of causal inference design), we consulted a third (independent) scientist and discrepancies were solved by discussion. The results from the data extraction are summarized in a results table (see Appendix A1). 


\section{Results}

\subsection{Brief characterization of included studies}

\section{Research interest}

Among the considered interventions, social comparison has attracted the most research attention. While 20 independent studies tested at least one social comparison treatment, only nine evaluate the effects of goal setting and commitment. In the following analysis, we evaluate the latter two interventions together since most relevant studies are overlapping. Additionally, nine studies assess the impact of labeling. In terms of available treatment effects, the analysis of our systematic review can rely on 37 documented effects for social comparison, 26 for goal setting and commitment, and 26 for labeling. The difference in numbers between articles and treatment effects is due to the fact that many studies consider more than one relevant intervention or evaluate multiple versions of the intervention in question.

Regarding the studies' publication dates an interesting pattern emerges. While the peak of research interest in goal setting and commitment was in the 1980s, followed by a longer neglect and a recent rediscovery, ${ }^{5}$ labeling has been largely neglected up till 2011. Since then, we observe a growing academic interest in analyzing the impact of the intervention. Similarly, research interest in the causal effects of social comparison on energy consumption behavior is fairly recent: the overwhelming majority of studies was published after the year 2004, with $70 \%$ of studies in this subsample (14 articles) being more recent than 2010.

\section{Methods}

For social comparison and goal setting/commitment, one dominant method is applied, namely the evaluation via randomized controlled trials (RCT). This methodology not only produces a high internal validity but also has advantages in terms of external validity as it (in most studies) observes real-life behavior. In contrast, most of the

\footnotetext{
${ }^{5}$ Two thirds of studies were published between 1978 and 1989, the remaining third since the year 2002.
} 
studies on labeling are conducted as laboratory experiments or choice-experiments within online-surveys, which have low external validity. Specifically, researchers ask subjects, for instance, which appliance they would choose in a set of choices and attribute differences in choice patterns to the way the choice set is presented (which differs between control and treatment group). Obviously, such choices are not real purchases but rather decisions within a hypothetical and limited choice set. It is thus not certain whether the reported effects would also occur in a real world setting, and results should be treated with caution despite their high internal validity. However, a few studies also exploit a policy change as a natural experiment or conduct an RCT with a labeling intervention.

\section{Geographical location}

Most of the studies identified by the systematic review are located in the US. This is especially true for goal setting/commitment, which up to date only has been evaluated in the US and the Netherlands. For social comparison and labeling, studies are conducted in several countries, for instance Japan, Australia, Finland and Great Britain. The majority of published research on the two interventions, however, also targets a study population in the US.

\section{Combination of interventions}

For social comparison and goal setting/commitment, almost all studies combine the considered interventions with other treatments. This poses an immense challenge for identifying the actual effect of the intervention. It moreover makes it difficult to compare effects from different studies, as they do not evaluate the same treatment. Figure 2 shows that energy savings tips and a comparison of usage history are most popular among treatment combinations (see Figure 2). Within the sub-sample of studies that allow identification of the pure effect by not combining the intervention with additional treatments, other limitations apply. For instance, the relevant social comparison studies suffer from methodological shortcomings (e.g. no reported effect sizes). For goal setting and commitment devices, there are substantial differences 
regarding the intensity of the treatment, because the required level of the goal varies as well as the criterion whether the level was self-selected or externally set. All in all this prohibits arriving at a coherent picture regarding the existing empirical evidence on the pure effects of the considered interventions.

Figure 2: Additional interventions combined with social comparison and with goal setting/commitment treatment

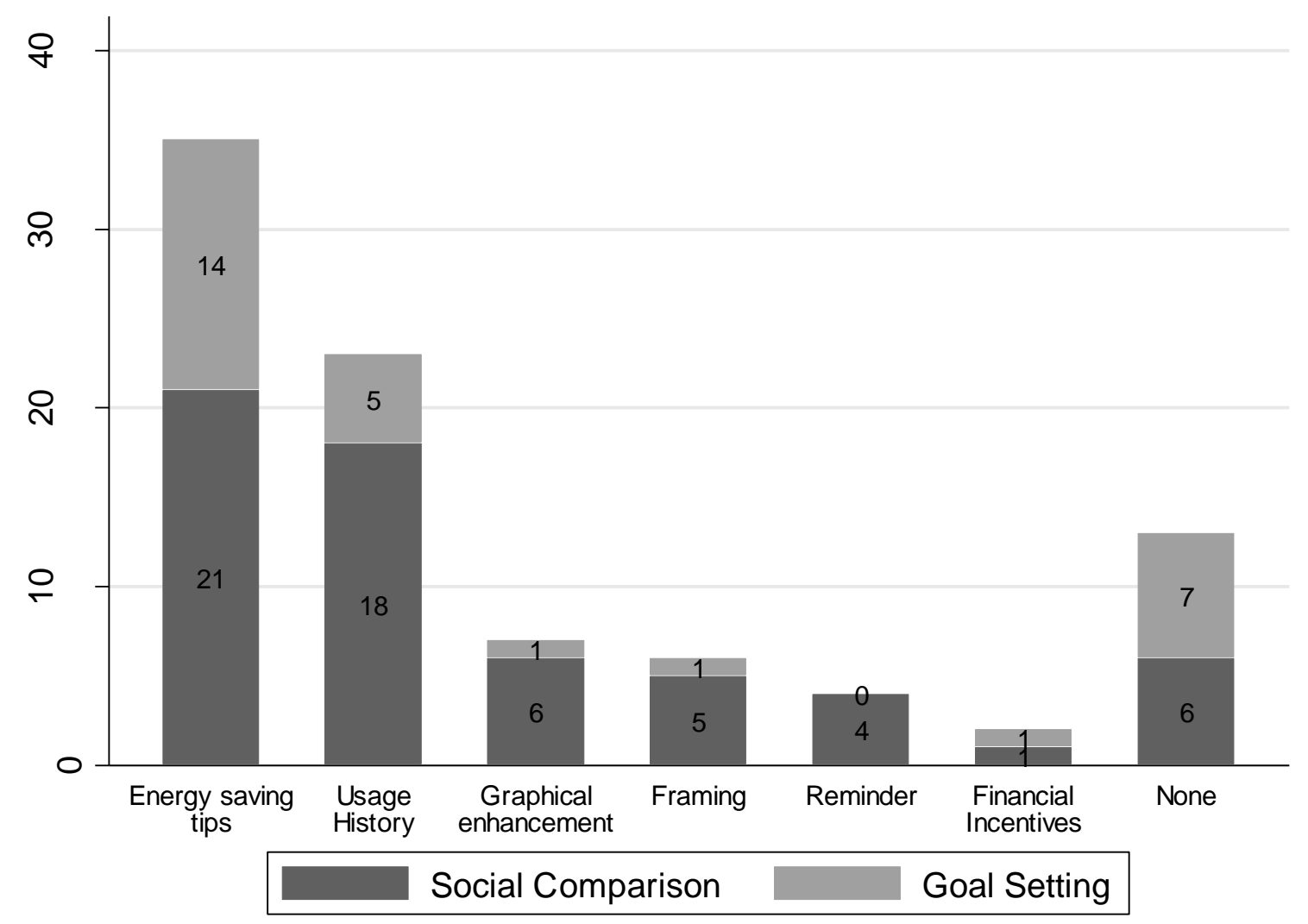

\section{Outcomes}

The vast majority of studies on social comparison and goal setting/commitment focus on actual or self-assessed energy consumption as their outcome of interest. For labeling, the case is different. Most studies evaluate the effect of labels on the willingness to pay for energy efficient appliances, followed by studies on an estimation of the energy savings potential or hypothetical purchase decisions regarding energy efficient appliances (see Figure 3). Only one labeling-study looks at actual energy consumption. Consequently, the quality of empirical evidence differs between the 
interventions: While the majority of labeling studies are based on stated preferences approaches (with their well-known limitation of hypothetical nature compared to revealed preferences), for the other interventions most studies analyze real behavior.

\section{Figure 3: Analyzed outcomes in studies with a labeling treatment}

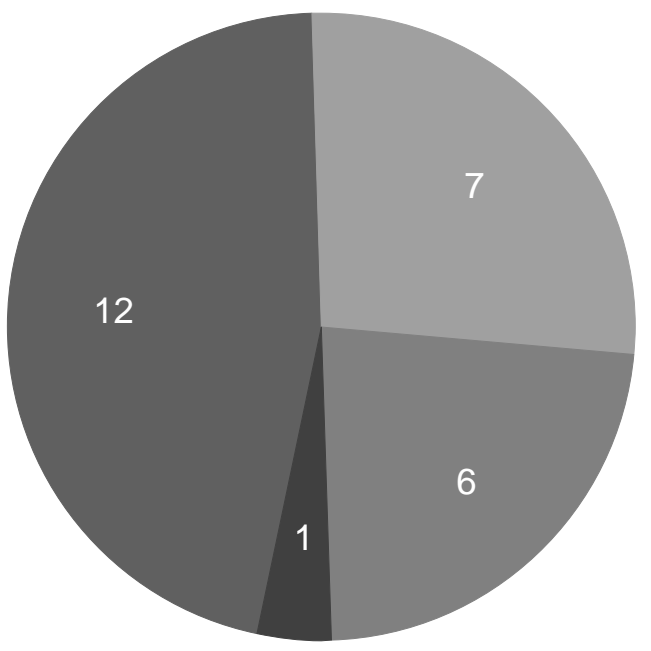

WTP for energy

efficient appliance

Correct estimation

Purchase probability of energy efficient appliance

\subsection{Synthesis of the evidence}

\subsubsection{Social Comparison}

Overall, the empirical evidence suggests that social comparison is an effective treatment. All but two of the 20 studies present statistically significant results in at least one of their analyzed treatment groups. ${ }^{6}$ A social comparison intervention results in a reduced energy consumption of private households ranging from $1.2 \%$ to $30 \%$ compared to the control group (see Figure 4). The only study showing an increase in energy usage level is Schultz et al. (2007) in one of their treatment groups. Yet, the respective treatment group was deliberately restricted to low users only, demonstrating the so called boomerang effect, i.e. that a social comparison can lead to

\footnotetext{
${ }^{6}$ The study of Hakaana et al. (1997) is not considered in this regard, as the article does not report any significance levels at all.
} 
adverse effects for the group that performs well in the comparison. They additionally show that the boomerang effect can be eliminated by adding an injunctive message. With regard to other outcomes, Komatsu and Nishio (2015) find a significant (positive) effect of the social comparison treatment on the motivation to conserve energy.

Figure 4: Estimated Effects of Social comparison by medium

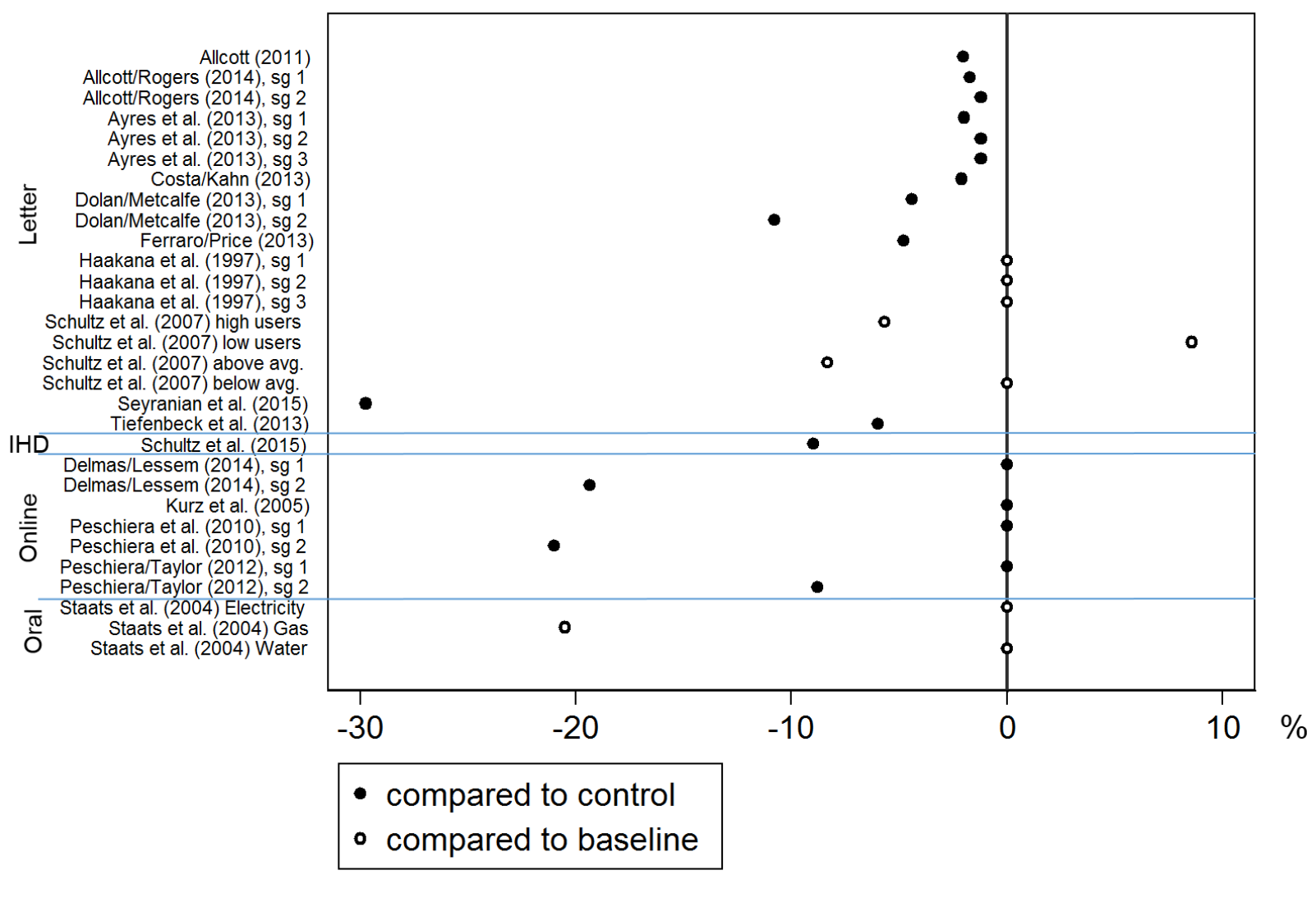

Note: Studies are sorted by treatment-medium and in alphabetical order. Effects of studies that do not report significance levels are depicted as nil-effects. "sg" and "avg" stand for "study group" and "average", respectively. Comment: The studies of Komatsu and Nishio (2015) and Kantola et al. (1984) are not included in the graph as they do not mention the magnitude of the measured significant conservation effects.

The heterogeneity of effects may be attributed to the medium via which the household receives the social comparison. As a tendency, we observe that online and In-Home-Display (IHD) treatments seem to result in a higher effect than letters. However, IHD-social comparisons are still underresearched. Another noteworthy fact 
is that studies with higher sample sizes (above 80,000) find smaller effects (around 2\%).

Both observations are compatible with existing evidence from previous reviews (Karlin et al. 2015).

One specific intervention design, the social comparison based "home energy reports" (HER) by the private company "Opower", has attracted major research attention. Opower cooperates with numerous US-energy suppliers and mails the HER to more than ten million households in the United States with the aim of reducing electricity consumption. The HER is a two-page letter with a bar graph comparing the household's energy consumption to its geographically nearest neighbors in similar house sizes on the first page and energy saving tips on the second page. Several high quality studies in this review (Allcott 2011; Ayres et al. 2013; Costa and Kahn 2013; Allcott and Rogers 2014) report significant, yet modest reduction effects. The empirical evidence for this specific intervention is outstanding as the internal and external validity for the US is high, long-term effects are documented and cost-benefit analyses are conducted. ${ }^{7}$ The numerous high quality studies can be seen as best practice for the evaluation of an intervention at large scale.

In all studies, in which a comparison of two similar combinations of interventions is possible, the effect increases when social comparison is added to the treatment (Ferraro and Price 2013; Mizobuchi and Takeuchi 2013). Moreover, Schultz et al. (2015) find a significant reduction in energy consumption of $9 \%$ compared to an insignificant treatment effect, when social comparison is added to the initial treatment intervention.

\footnotetext{
${ }^{7}$ On the basis of 111 RCTs that evaluate the HER, Allcott (2015) shows that even for the exceptional case that there exists many replications, program evaluations can still give systematically biased out-of-sample predictions due to a "site selection bias". In this example, predictions from the first 10 replications substantially overstate efficacy because, among others, utilities in more environmentalist areas are more likely to adopt the program, their customers are more responsive to the treatment, and utilities initially target their treatment at higher-usage consumer subpopulations. In a very recent study, Andor et al. (2017) show that social comparison based home energy reports are most likely not a cost effective climate policy instrument in many countries, in particular in Europe, due to lower electricity consumption levels and carbon intensities. For a study population in Germany, they additionally measure a substantially smaller treatment effect of social comparison based home energy reports.
} 
The only two studies that aim to identify the pure effect of social comparison have methodological limitations. Haakana et al. (1997) find that a pure social comparison treatment shows similar or smaller effects as a social comparison with energy savings tips. The study, however, provides no information about significance levels for any of the effects. Komatsu and Nishio (2015) analyze the self-assessment on one's own consumption in regard to the neighbors' consumption and the own motivation to conserve energy. They find ambiguous effects of the social comparison treatment, but do not report effect sizes. Moreover, the analysis is not based on actual behavior but solely relies on self-assessments.

Some studies suggest that social comparison might also trigger adverse effects. Schultz et al. (2007) show that low users significantly increased their energy consumption after having learned that they are below-average users. This raises important questions regarding a tailored application of social comparison treatments. Furthermore, Tiefenbeck et al. (2013) investigate side-effects of a social comparison treatment. They find a significant reduction in water consumption of $6 \%$ after they provided weekly feedback about water consumption levels per capita, accompanied by a social comparison with the most efficient $10 \%$ of users, and tips about how to conserve water. At the same time, the electricity consumption of the treatment group increased by $5.6 \%$. This result might be seen as first evidence of the so called moral self-licensing effect, the phenomenon that past good deeds favor a positive selfperception that in turn creates licensing effects, leading people to engage in behavior that is less likely to be in line with their moral values (Nisan and Horenczyk 1990). If such side-effects occur, it is not clear whether an intervention induces sustainable behavior in a broader sense, even if the estimated treatment effect suggests a reduction of the 'direct' outcome (in this example: water consumption).

In regard to long-term-effects, no clear picture emerges. Several studies document a reinforcement of effects in the long-run for some of their treatment groups (Delmas and Lessem 2014; Allcott and Rogers 2014; Dolan and Metcalfe 2013; Schultz 
et al. 2007). In Staats et al. (2004), two initially insignificant short-term effects increase and become significantly different from the control group when measured two years after the intervention stopped. In other studies, treatment effects decrease (Ferraro et al. 2011; Schultz et al. 2015; Staats et al. 2004; Schultz et al. 2007), remain or become insignificant (Delmas and Lessem 2014; Dolan and Metcalfe 2013; Tiefenbeck et al. 2013; Schultz et al. 2007). It would be desirable to identify the driving factors for these heterogeneous effects. Yet, based on the existing empirical evidence, we do not observe any obvious indications. ${ }^{8}$ As long-term-effects are crucial for the cost-effectiveness of the interventions, their analysis should be one focus of future research.

In sum, social comparison presents an effective treatment. Yet, researchers and policy makers should closely monitor potential adverse effects on certain subgroups of households (below-average users) and on consumption patterns regarding other goods (moral licensing effect). Furthermore, the analysis of long-term-effects and costbenefit-analysis should be an inherent part of the impact evaluation.

\subsubsection{Goal Setting and Commitment Devices}

Many of the identified studies on goal setting and commitment suffer from methodological shortcomings, despite satisfying the criterion of applying a methodology suitable to identify a causal effect. For instance, they test several treatments in their RCT despite relying on very small study samples, or they do not report significance levels of results. Thus, the picture regarding an assessment of treatment effects is not quite clear: more than half of the documented effects are not significantly different from zero or cannot be depicted as such because no significance level is reported (see Figure 5). The reason for this may either be that the treatment

\footnotetext{
${ }^{8}$ In a recent study, Brandon et al. (2017) explore the underlying mechanisms of long-run reductions in energy consumption induced by a social comparison (specifically the HER by Opower, see above). Using the data of 38 natural field experiments, they find that the physical capital channel (e.g. insulating the house or buying a more energy efficient washing machine) is more important for the persistence of effects than habit formation within the household.
} 
actually has no effect, or that the study's features (in particular a not sufficiently powered sample) contribute to the result.

Figure 5: Goal setting/commitment-effects by self-set or externally set goal

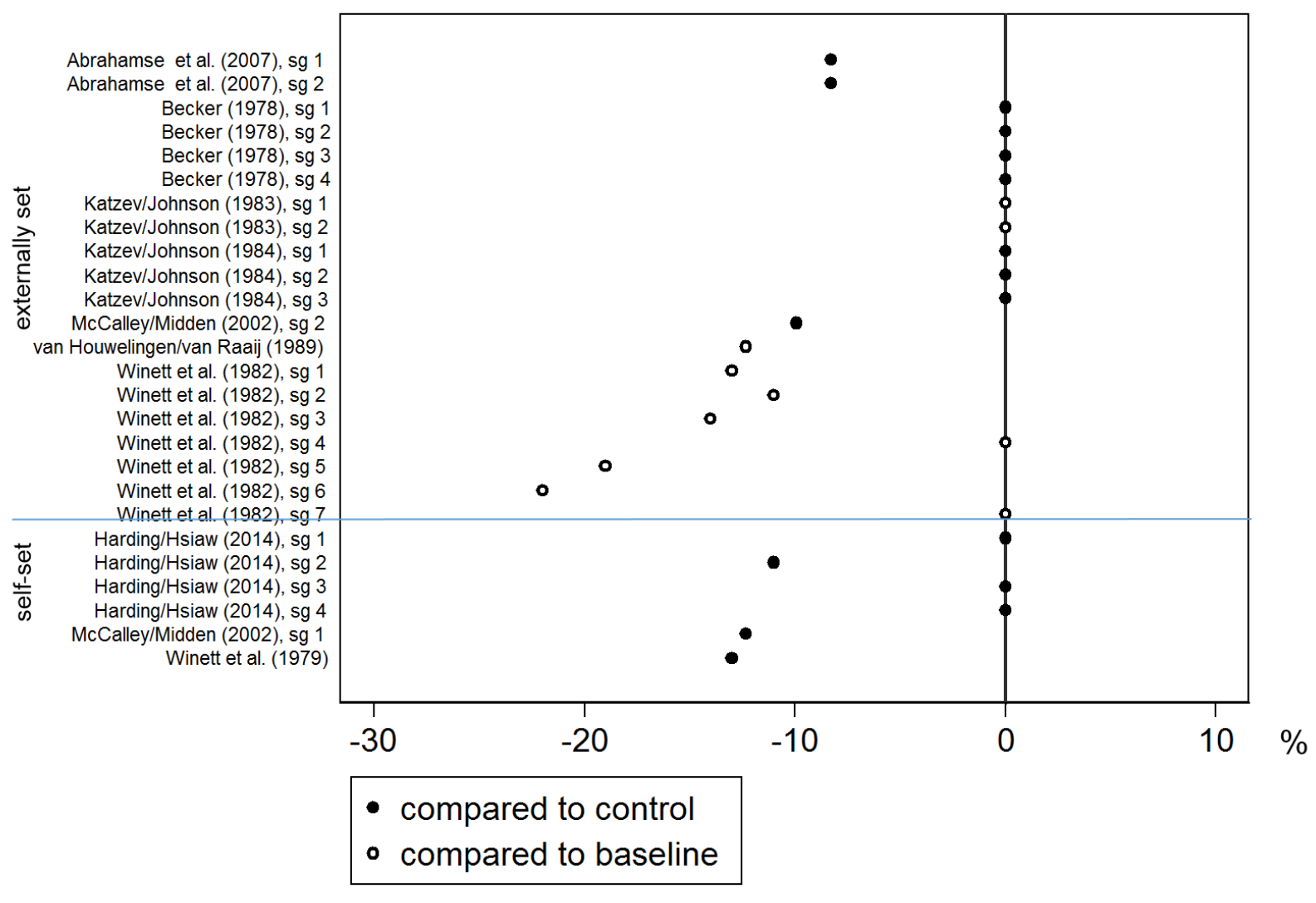

Note: Studies are sorted by self-set and externally set goals/commitments and in alphabetical order. Effects of studies that do not report significance levels are depicted as nil-effects. "sg" stands for "study group".

Interpreting the results of the identified studies, self-set goals seem to result in a significant reduction effect when they are chosen realistically (Harding and Hsiaw 2014; McCalley and Midden 2002; Winett et al. 1979). Harding and Hsiaw (2014) report from a field study with more than 12,000 households that the sub-sample selecting the achievable goal of energy conservation between $0 \%$ and $15 \%$ reduced their consumption by $11 \%$. The authors still measure a significant reduction effect after 18 months. At the same time, the treatment group that selected a more optimistic goal (15\%-50\%) also saved energy shortly after the start of the program. However, their effort vanished after they received feedback about their usage development, 
presumably because they realized that it would be impossible to achieve the ambitious goal. In contrast, both sub-samples choosing either a zero-goal or a more-than-50\% goal showed no behavior change at all. However, we have to note that the results could be caused by self-selection: people who are in general more motivated to conserve energy could have selected themselves into more realistic goals, while people who are generally unwilling to change their behavior chose zero or unrealistically ambitious goal levels.

Goals that are externally set by the experimenters have resulted in either insignificant effects or energy savings up to $22 \%$ compared to baseline consumption (Figure 4). Many of the reported significant effects stem from Winett et al. (1982), who conducted two RCT studies, but with a relatively small sample size of in total 83 households for five treatment groups. After having taken part in a meeting, researchers asked participants to sign a commitment to reduce their energy consumption by $15 \%$ within the next 35 days. In addition to frequent feedback about their progress, households received an audio tape with tips on how to save energy. One study was conducted during winter, the other one during summer. All but one of six treatment groups showed significant and relatively high reduction effects ranging from $11 \%$ to $22 \%$.

In another study, an externally set goal of $10 \%$ resulted in a significant energy conservation effect of about 12.3\% (van Houwelingen and van Raaj 1989). The effect remained significant one year after the intervention. Abrahamse et al. (2007) measure a smaller, but still significant effect of a 5\%-goal in their RCT. In addition to these findings, a laboratory study by McCalley and Midden (2002) points to energy saving potential of externally set goals of around $20 \%$.

On the other hand, Becker (1978) as well as Katzev and Johnson (1984) were not able to confirm significant effects of external goal setting in the field. Yet, in another study, Katzev and Johnson (1983) find that insignificant effects in the short-run become significant in the long-run. 
In sum, goal setting and commitment still need substantial research efforts. The significant results point to a relatively high energy conservation potential of around $10 \%$, while at the same time we cannot rule out that many of the insignificant results are due to underpowered samples. It seems to be a promising avenue for further research to evaluate the effect of energy conservation goals with a well-powered study set up, especially goals that are externally set.

\subsubsection{Labeling}

All but two of the identified studies on labeling report significant results in at least a subsample of their study population. Regarding effect sizes, they also point to potentially pronounced effects of labeling.

Five studies evaluate the effect of labels under real-world conditions. Brounen and Kok (2011) document significantly higher sales prices for houses with a "green" energy efficiency EU-label (classes A, B, C) than for comparable houses without such a label. Houde (2014) exploits two natural experiments concerning the Energy Star Label. He observes a significantly higher willingness to pay for refrigerators when they have the label. His analysis is based on a comparison of the same models of refrigerators before and after the criteria of the Energy Star Label were tightened. In the second study, the measured positive effect of the Energy Star Label on the willingness to pay for refrigerators is not significant. In a similar vein, Allcott and Taubinsky (2015) cannot find a significant effect of a label on the probability to purchase an energy-saving lightbulb in their RCT in a big electrical store in the US. In the study by Kurz et al. (2005), which provided the treatment group with labels on the consumption levels of the household's own appliances, effects range from zero to a reduced energy consumption of $23 \%$.

The choice experiment of Heinzle (2012) shows that the willingness to pay for a more efficient TV significantly increases when consumers are given information on absolute operating costs over the course of ten years. However, it significantly decreases when the label provides information on annual operating costs. Study 
participants in a further hypothetical choice experiment of Newell and Siikamäki (2014) show a significantly lower willingness to pay compared to the potential savings they could gain by operating a more efficient warm water processors when they only received information on consumption costs and $\mathrm{CO} 2$-emissions. Yet, once this information was accompanied by an Energy Star Label, the willingness to pay increased above the cost effective level.

Waechter et al. (2015), moreover, show that energy efficiency classes strongly influence the consumer's estimation of the energy consumption level of appliances, to the extent that people will make decisions based on the energy efficiency class even when concrete and readily apparent consumption information contradicts it. In addition, Ölander and Thøgersen (2014) provide evidence for the positive effect of visualizing information in form of a simple label: changing an energy efficiency scale from a complex "A+++ - D"-system to a simpler "A - G" more than doubled the probability that an energy-efficient device would be chosen.

In sum, even though up to now there is not a vast amount of research on labeling, we identify a remarkable potential of the intervention. Not only do hypothetical purchase decisions in choice experiments confirm their effectiveness, but so too do evaluations of labels in the field. Future research should focus on different elements of labels, like the framing of costs or the mode of ranking, and test their separate and combined effects in the field.

\section{Discussion and Conclusion}

This paper conducted a systematic review of behavioral interventions to induce residential energy conservation. In contrast to the existing literature, this review focused on studies that permit the identification of the causal relationship between the intervention and the outcome of interest. In addition, it is the first review to cover labeling, an intervention that affects millions of people worldwide. 
We find that all four interventions have the potential to significantly reduce energy consumption of private households. While the vast majority of studies documents a significant reduction effect for the social comparison intervention, results for the other interventions are mixed. Social comparison has been the most researched intervention, in terms of both quality and quantity. In particular, the several "Opower studies" that investigate the causal effect of social comparison based home energy reports on energy consumption deliver broad empirical evidence and can be seen as best practice for program evaluations of energy conservation interventions. Yet, even for this intervention, many open questions remain: What is the actual pure effect of social comparison? Under which circumstances do social comparisons cause adverse effects? How much does the effect of social comparison interact with the medium by which it is delivered? First evidence on these questions indicate that adverse effects seem to matter and that it can make a difference if the social comparison is delivered by a letter, electronically online or via IHD.

Pre-commitment and goal setting have not yet been researched extensively, and existing studies show major methodological shortcomings mainly in terms of underpowered samples. Yet, studies that document significant effects show conservation potential of around $10 \%$. It is thus a promising avenue for further research to evaluate these interventions with a sufficiently large study sample, preferably in the field.

Although energy labels are applied worldwide, labeling is a very recent field of research. First evidence shows that labels can be effective with regard to the perception of and the willingness to pay for energy efficiency. Early results by laboratory experiments are confirmed by some first field studies. Because the existing empirical evidence is mostly based on stated preference approaches, though, a promising field of future research is the evaluation of the effects of labels by analyzing revealed preferences. 
The review moreover clearly shows that the amount of studies that satisfy the quality criterion of causal inference increased in the last few years. There are presumably three reasons for this development: the improving quality of empirical research, an increasing interest in behavioral economics, and the need to find effective interventions to trigger energy conservation. However, there is still a lot to be done. Although we focused on 'higher quality' studies that are potentially able to identify causal effects, only few studies within the sample contain evidence to back up concrete policy recommendations. Obstacles are, for instance, insufficiently powered sample sizes, poor reporting of statistical tests, and study populations that are different from the target population. Furthermore, the minority of studies discusses the benefits and costs of the intervention, a prerequisite to give policy recommendations.

To sum up, we are surprised how little we know. We therefore call for systematic evaluations of these and similar interventions potentially able to trigger energy conservation before a large-scale rollout. It seems surprising that an intervention such as labeling is applied worldwide but there is little knowledge about the actual impact.

Future studies should focus on at least three crucial points: First, assess the causal effect of the intervention with a suitable methodology and a sufficiently powered sample that enables identification of even small effects with statistical precision. Second, researchers should refrain from combining too many different treatments. We need evidence on the pure effect of the chosen interventions before we begin to potentially reinforce this effect by additional treatments. Third, long-term effects of the intervention should be analyzed and the intervention costs should be documented in order to enable a careful cost-benefit-analysis on the treatment's effectiveness. At best, interventions should be ex-ante evaluated before they are rolled out at large-scale, for instance by randomized field experiments within the target population. 


\section{Literature}

Abrahamse, W., Steg, L., Vlek, C., and Rothengatter, T. (2005). A review of intervention studies aimed at household energy conservation. Journal of environmental psychology 25(3), 273-291.

Abrahamse, W., Steg, L., Vlek, C., and Rothengatter, T. (2007). The effect of tailored information, goal setting, and tailored feedback on household energy use, energy-related behaviors, and behavioral antecedents. Journal of Environmental Psychology 27 (4), 265-276. DOI:

10.1016/j.jenvp.2007.08.002.

Allcott, H., and Mullainathan, S. (2010). Behavior and energy policy. American Association for the Advancement of Science 327 (5970), 1204-1205. DOI: 10.1126/science.1180775.

Allcott, H. (2011). Social norms and energy conservation. Journal of Public Economics 95 (9-10), 10821095. DOI: $10.1016 / j$ jpubeco.2011.03.003.

Allcott, H. (2015) Site selection bias in program evaluation. The Quarterly Journal of Economics 130 (3), 1117-1165.

Allcott, H., and Rogers, T. (2014). The short-run and long-run effects of behavioral interventions: Experimental evidence from energy conservation. American Economic Review 104 (10), 3003-3037. DOI: 10.1257/aer.104.10.3003.

Allcott, H., and Kessler, J.B. (2015). The welfare effects of nudges: A case study of energy use social comparisons (NBER Working Paper No. 21671). National Bureau of Economic Research.

Allcott, H., and Taubinsky, D. (2015). Evaluating behaviorally motivated policy: Experimental evidence from the lightbulb market. American Economic Review 105 (8), 2501-2538. DOI:

10.1257/aer.20131564.

Andor, M., Gerster, A., Peters, J., and Christoph M. Schmidt (2017). Social norms and energy conservation beyond the US. Discussion Paper.

Angrist, J.D., and Pischke, J.-S. (2009). Mostly harmless econometrics: An empiricists' companion. Princeton university press.

Aste, N., Adhikari, R.S., and Manfren, M. (2013). Cost optimal analysis of heat pump technology adoption in residential reference buildings. Renewable Energy 60, 615-624. DOI: 10.1016/j.renene.2013.06.013.

Ayres, I., Raseman, S., and Shih, A. (2013). Evidence from two large field experiments that peer comparison feedback can reduce residential energy usage. Journal of Law, Economics, and Organization 29 (5), 992-1022. DOI: 10.1093/jleo/ews020.

Bandura, A. (1986). Social foundations of thought and action: A social cognitive theory, Prentice Hall.

Bauwens, L., Fiebig, D.G., and Steel, M.F.J. (1994). Estimating end-use demand: A bayesian approach. Journal of Business and Economic Statistics 12 (2), 221-231.

Becker, L.J. (1978). Joint effect of feedback and goal setting on performance: A field study of residential energy conservation. Journal of Applied Psychology 63 (4), 428-433. DOI: 10.1037/00219010.63.4.428.

Bedwell, B., Leygue, C., Goulden, M., McAuley, D., Colley, J., and Ferguson, E. (2014). Apportioning energy consumption in the workplace: A review of issues in using metering data to motivate staff to save energy. Technology Analysis and Strategic Management 26 (10), 1196-1211. 
Brandon, A., Ferraro, P.J., List, J.A., Metcalfe, R.D., Price, M.K., and F. Rundhammer (2017): Do The Effects of Social Nudges Persist? Theory and Evidence from 38 Natural Field Experiments. (NBER Working Paper No. 23277).

Brounen, D., and Kok, N. (2011). On the economics of energy labels in the housing market. Journal of Environmental Economics and Management 62 (2), 166-179. DOI: 10.1016/j.jeem.2010.11.006.

Brutscher, P.-B. (2011). Payment matters? An exploratory study into the pre-payment electricity metering.

Buchanan, K., Russo, R., and Anderson, B. (2014). Feeding back about eco-feedback: How do consumers use and respond to energy monitors? Special Section: Carbon Reduction at Community Scale 73, 138-146. DOI: 10.1016/j.enpol.2014.05.008.

Campbell Collaboration (2014). Campbell Systematic Reviews: Policies and Guidelines, Campbell Systematic Reviews 2014: Supplement 1.

Costa, D.L., Kahn, M.E. (2013). Energy conservation 'nudges' and environmentalist ideology: Evidence from a randomized residential electricity field experiment. Journal of the European Economic Association 11 (3), 680-702. DOI: 10.1111/jeea.12011.

Darby, S. (2006). Social learning and public policy: Lessons from an energy-conscious village. Special Section: Carbon Reduction at Community Scale 34 (17), 2929-2940. DOI: 10.1016/j.enpol.2005.04.013.

Delmas, M.A., Fischlein, M., and Asensio, O.I. (2013). Information strategies and energy conservation behavior: A meta-analysis of experimental studies from 1975 to 2012. Energy Policy 61, 729-739. DOI: 10.1016/j.enpol.2013.05.109.

Delmas, M.A., and Lessem, N. (2014). Saving power to conserve your reputation? The effectiveness of private versus public information. Journal of Environmental Economics and Management 67 (3), 353370. DOI: 10.1016/j.jeem.2013.12.009.

Di Cosmo, V., Lyons, S., and Nolan, A. (2014). Estimating the impact of time-of-use pricing on irish electricity demand. Energy Journal 35 (2), 117-136.

Dogan, E., Bolderdijk, J.W., and Steg, L. (2014). Making small numbers count: environmental and financial feedback in promoting eco-driving behaviours. Journal of Consumer Policy 37 (3), 413-422.

Dolan, P., and Metcalfe, R. (2013). Neighbors, knowledge, and nuggets: Two natural field experiments on the role of incentives on energy conservation (Economics Working Paper No. 2589269). Becker Friedman Institute for Research. DOI: 10.2139/ssrn.2589269.

Dowd, A., Ashworth, P., Carr-Cornish, S., and Stenner, K. (2012). Energymark: Empowering individual Australians to reduce their energy consumption. Special Section: Carbon Reduction at Community Scale 51, 264-276. DOI: 10.1016/j.enpol.2012.07.054.

Ferraro, P.J., Miranda, J.J., and Price, M.K. (2011). The persistence of treatment effects with normbased policy instruments: evidence from a randomized environmental policy experiment. The American Economic Review 101 (3), 318-322. DOI: 10.1257/aer.101.3.318.

Ferraro, P.J., and Price, M.K. (2013). Using nonpecuniary strategies to influence behavior: Evidence from a large-scale field experiment. Review of Economics and Statistics 95 (1), 64-73. DOI: 10.1162/REST_a_00344.

Frondel, M., and Vance, C. (2013). Energy efficiency: Don't belittle the rebound effect. Nature 494, 430-430. DOI: $10.1038 / 494430$ c 
Haakana, M., Sillanpaeae, L., and Talsi, M. (1997). The effect of feedback and focused advice on household energy consumption. Paper presented at the Summer Study of the European Council for an Energy Efficient Economy.

Harding, M., and; Hsiaw, A. (2014). Goal setting and energy conservation. Journal of Economic Behavior and Organization 107, 209-227. DOI: 10.1016/j.jebo.2014.04.012.

Hargreaves, T., Nye, M., and Burgess, J. (2010). Making energy visible: A qualitative field study of how householders interact with feedback from smart energy monitors. Special Section: Carbon Reduction at Community Scale 38 (10), 6111-6119. DOI: 10.1016/j.enpol.2010.05.068.

Hargreaves, T., Nye, M., and Burgess, J. (2013). Keeping energy visible? Exploring how householders interact with feedback from smart energy monitors in the longer term. Special Section: Carbon Reduction at Community Scale 52, 126-134. DOI: 10.1016/j.enpol.2012.03.027.

Heberlein, T.A., and Warriner, G.K. (1983). The influence of price and attitude on shifting residential electricity consumption from on- to off-peak periods. Journal of Economic Psychology 4 (1-2), 107-130. DOI: 10.1016/0167-4870(83)90048-X.

Heinzle, S.L. (2012). Disclosure of energy operating cost information: A silver bullet for overcoming the energy-efficiency gap? Journal of Consumer Policy 35 (1), 43-64. DOI: 10.1007/s10603-012-9189-6.

Houde, S. (2014). How consumers respond to environmental certification and the value of energy information (NBER Working Paper No. 20019). National Bureau of Economic Research. DOI: 10.3386/w20019.

Houde, S., and Aldy, J.E. (2014). Belt and suspenders and more: the incremental impact of energy efficiency subsidies in the presence of existing policy instruments (NBER Working Paper No. 20541). National Bureau of Economic Research.

Houwelingen, J.H. van, and van Raaij, W.F.(1989). The effect of goal-setting and daily electronic feedback on in-home energy use. Journal of Consumer Research 16 (1), 98-105. DOI: 10.1086/209197.

Imbens, G.W., and Wooldridge, J.M. (2009). Recent developments in the econometrics of program evaluation. Journal of Economic Literature 47 (1), 5-86. DOI: 10.1257/jel.47.1.5

Ivanov, C., Getachew, L., Fenrick, S.A.,and Vittetoe, B. (2013). Enabling technologies and energy savings: The case of EnergyWise Smart Meter Pilot of Connexus Energy. Utilities Policy 26, 76-84. DOI: 10.1016/j.jup.2012.10.001.

Kahneman, D. (2003). Maps of bounded rationality: Psychology for behavioural economics. The American Economic Review 93 (5), 1449-1475.

Kantola, S.J., Syme, G.J., and Campbell, N.A. (1984). Cognitive dissonance and energy conservation. Journal of Applied Psychology 69 (3), 416-421. DOI: 10.1037/0021-9010.69.3.416.

Karlin, B., Ford, R., and Zinger, J. (2015). The effects of feedback on energy conservation: A metaanalysis. Psychological Bulletin 141, 1205-1247.

Katzev, R.D., and Johnson, T.R. (1983). A social-psychological analysis of residential electricity consumption: The impact of minimal justification techniques. Journal of Economic Psychology 3 (3-4), 268-284. DOI: 10.1016/0167-4870(83)90006-5.

Katzev, R.D., and Johnson, T.R. (1984). Comparing the effects of monetary incentives and foot-inthe-door strategies in promoting residential electricity conservation. Journal of Applied Social Psychology 14 (1), 12-27. DOI: 10.1111/j.1559-1816.1984.tb02217.x.

Komatsu, H., and Nishio, K. (2015). An experimental study on motivational change for electricity conservation by normative messages. Applied Energy 158, 35-43. DOI: 10.1016/j.apenergy.2015.08.029. 
Kurz, T., Donaghue, N., and Walker, I. (2005). Utilizing a social-ecological framework to promote water and energy conservation: A field experiment. Journal of Applied Social Psychology 35 (6), 12811300. DOI: 10.1111/j.1559-1816.2005.tb02171.x.

Lang, C., and Okwelum, E. (2015). The mitigating effect of strategic behavior on the net benefits of a direct load control program. Energy Economics 49, 141-148.

Litvine, D., and Wustenhagen, R. (2011). Helping 'light green' consumers walk the talk: Results of a behavioural intervention survey in the Swiss electricity market. Ecological Economics 70 (3), 462-474.

Lokhorst, A.M., Werner, C., Staats, H., van Dijk, E., and Gale, J.E. (2013). Commitment and behavior change: A meta-analysis and critical review of commitment-making strategies in environmental research. Environment and Behavior 45(1), 3-34.

Lutzenhiser, L. (1992). A cultural model of household energy consumption. Energy 17 (1), 47-60. DOI: 10.1016/0360-5442(92)90032-U.

McCalley, L.T., and Midden, C.J.H. (2002). Energy conservation through product-integrated feedback: The roles of goal-setting and social orientation. Journal of Economic Psychology 23 (5), 589603. DOI: 10.1016/S0167-4870(02)00119-8.

Midden, C.J.H., and Ritsema, B.S.M. (1983). The meaning of normative processes for energy conservation. Journal of Economic Psychology 4 (1-2), 37-55. DOI: 10.1016/0167-4870(83)90044-2.

Mills, B., and Schleich, J. (2010). What's driving energy efficient appliance label awareness and purchase propensity? At the Crossroads: Pathways of Renewable and Nuclear Energy Policy in North Africa 38 (2), 814-825. DOI: 10.1016/j.enpol.2009.10.028.

Mizobuchi, K., and Takeuchi, K. (2013). The influences of financial and non-financial factors on energy-saving behaviour: A field experiment in japan. Energy Policy 63, 775-787. DOI: 10.1016/j.enpol.2013.08.064.

Murtagh, N. (2013). Individual energy use and feedback in an office setting: A field trial. Energy Policy 62, 717-728.

Newell, R.G., and Siikamäki, J.V. (2014). Nudging energy efficiency behavior: The role of information labels. Journal of the Association of Environmental and Resource Economists, 1(4), 555-598. DOI: $10.3386 / \mathrm{w} 19224$.

Nisan, M., and G. Horenczyk (1990). Moral balance: The effect of prior behaviour on decision in moral conflict. British Journal of Social Psychology 29(1), 29-42.

O'Donoghue, T., and Rabin, M. (1999). Doing it now or later. The American Economic Review 89 (1), 103-124.

O'Donoghue, T., and Rabin, M. (2008). Procrastination on long-term projects. Journal of Economic Behavior \& Organization 66 (2), 161-175.

Oltra, C., Boso, A., Espluga, J., and Prades, A. (2013). A qualitative study of users' engagement with real-time feedback from in-house energy consumption displays. Special Section: Carbon Reduction at Community Scale 61, 788-792. DOI: 10.1016/j.enpol.2013.06.127.

Oseni, M.O., Pollitt, M. G., Reiner, D.M., Richter, L.L. Chyong, K., and Baddeley, M. (2013). 2013 EPRG public opinion survey: Smart energy survey - attitudes and behaviours.

Ölander, F., Thogerson, J. (2014). Informing versus nudging in environmental policy. Journal of Consumer Policy 37, 341-356. DOI: 10.1007/s10603-014-9256-2. 
Paetz, A.-G., Dutschke, E., and Fichtner, W. (2012). Smart homes as a means to sustainable energy consumption: A study of consumer perceptions. Journal of Consumer Policy 35 (1), 23-41.

Peschiera, G., Taylor, J.E., and Siegel, J.A. (2010). Response-relapse patterns of building occupant electricity consumption following exposure to personal, contextualized and occupant peer network utilization data. Energy and Buildings 42 (8), 1329-1336. DOI: 10.1016/j.enbuild.2010.03.001.

Peschiera, G., and Taylor, J.E. (2012). The impact of peer network position on electricity consumption in building occupant networks utilizing energy feedback systems. Energy and Buildings 42 (8), 1329- 1336. DOI: 10.1016/j.enbuild.2012.03.011.

Pullinger, M., Lovell, H., and Webb, J. (2014). Influencing household energy practices: A critical review of UK smart metering standards and commercial feedback devices. Technology Analysis and Strategic Management 26 (10), 1144-1162.

Richalet, V., Neirac, F.P., Tellez, F., Marco, J., and Bloem, J.J. (2001). HELP (house energy labeling procedure): Methodology and present results. Energy and Buildings 33 (3), 229-233. DOI: 10.1016/S0378-7788(00)00086-4.

Schubert, R., and Stadelmann, M. (2015). Energy-using durables - why consumers refrain from economically optimal choices. Frontiers in Energy Research 3 (7), 1-13. 10.3389/fenrg.2015.00007.

Schultz, P.W., Nolan, J.M., Cialdini, R.B., Goldstein, N.J., and Griskevicius, V. (2007). The constructive, destructive, and reconstructive power of social norms. Psychological Science 18 (5), 429 434. DOI: 10.1111/j.1467-9280.2007.01917.x.

Schultz, P. W., Estrada, M., Schmitt, J., Sokoloski, R., and Silva-Send, N. (2015). Using in-home displays to provide smart meter feedback about household electricity consumption: A randomized control trial comparing kilowatts, cost, and social norms. Energy 90, Part 1, 351-358. DOI: 10.1016/j.energy.2015.06.130.

Seyranian, V., Sinatra, G.M., and Polikoff, M.S. (2015). Comparing communication strategies for reducing residential water consumption. Journal of Environmental Psychology 41, 81-90. DOI: 10.1016/j.jenvp.2014.11.009.

Shen, M., Cui, Q., and Fu, L. (2015). Personality traits and energy conservation. Special Section: Carbon Reduction at Community Scale 85, 322-334. DOI: 10.1016/j.enpol.2015.05.025.

Staats, H., Harland, P., and Wilke, H.A.M. (2004). Effecting durable change: A team approach to improve environmental behavior in the household. Environment and Behavior 36, 341-367. DOI: $10.1177 / 001391650326016$.

Steg, L. (2008). Promoting household energy conservation. At the Crossroads: Pathways of Renewable and Nuclear Energy Policy in North Africa 36 (12), 4449-4453. DOI: 10.1016/j.enpol.2008.09.027.

Stillwater, T., and Kurani, K.S. (2013). Drivers discuss ecodriving feedback: Goal setting, framing, and anchoring motivate new behaviors. Transportation Research Part F: Traffic Psychology and Behaviour 19, 85-96. DOI: 10.1016/j.trf.2013.03.007.

Thaler, R.H., and Sunstein, C.R. (2008). Nudge: Improving decisions about health, wealth, and happiness. Yale University Press.

Tiefenbeck, V., Staake, T., Roth, K., and Sachs, O. (2013). For better or for worse? Empirical evidence of moral licensing in a behavioral energy conservation campaign. Energy Policy 57, 160-171. DOI: 10.1016/j.enpol.2013.01.021. 
Verplanken, B., and Weenig, M.W.H. (1993). Graphical energy labels and consumers' decisions about home appliances: A process tracing approach. Journal of Economic Psychology 14 (4), 739-752. DOI: 10.1016/0167-4870(93)90019-H.

Waechter, S., Sütterlin, B., and Siegrist, M. (2015). The misleading effect of energy efficiency information on perceived energy friendliness of electric goods. Carbon Emissions Reduction: Policies, Technologies, Monitoring, Assessment and Modeling 93, 193-202. DOI: 10.1016/j.jclepro.2015.01.011.

Wang, Z., Zhang, B., Yin, J., Zhang, Y. (2011). Determinants and policy implications for household electricity-saving behaviour: Evidence from Beijing, China. Special Section: Carbon Reduction at Community Scale 39 (6), 3550-3557. DOI: 10.1016/j.enpol.2011.03.055.

Winett, R.A., Neale, R.A., and Grier, H.C. (1979). Effects of Self-Monitoring and Feedback on Residential Electricity Consumption. Journal of Applied Behavior Analysis 12 (2), 173-184. DOI: 10.1901/jaba.1979.12-173.

Winett, R.A., Hatcher, J.W., Fort, T.R., Leckliter, I.N., Love, S.Q., Riley, A.W., and Fishback, J.F. (1982). The effects of videotape modeling and daily feedback on residential electricity conservation home temperatur and humidity, perceived comfort and clothing worn: winter and summer. Journal of Applied Behavior Analysis 15 (3), 381-402. DOI: 10.1901/jaba.1982.15-381.

Yeomans, M., and; Herberich, D. (2014). An experimental test of the effect of negative social norms on energy-efficient investments. Journal of Economic Behavior \& Organization 108, 187-197. DOI: 10.1016/j.jebo.2014.09.010.

Zhou, N, Fridley, D., McNeil, M., Zheng, N., Letschert, V., Ke, J., Saheb, Y. (2011). Analysis of potential energy saving and $\mathrm{CO} 2$ emission reduction of home appliances and commercial equipments in China. At the Crossroads: Pathways of Renewable and Nuclear Energy Policy in North Africa 39 (8), 4541-4550. DOI: 10.1016/j.enpol.2011.04.027. 


\section{Appendix A}

\section{Table A1: "Final Results Table"}

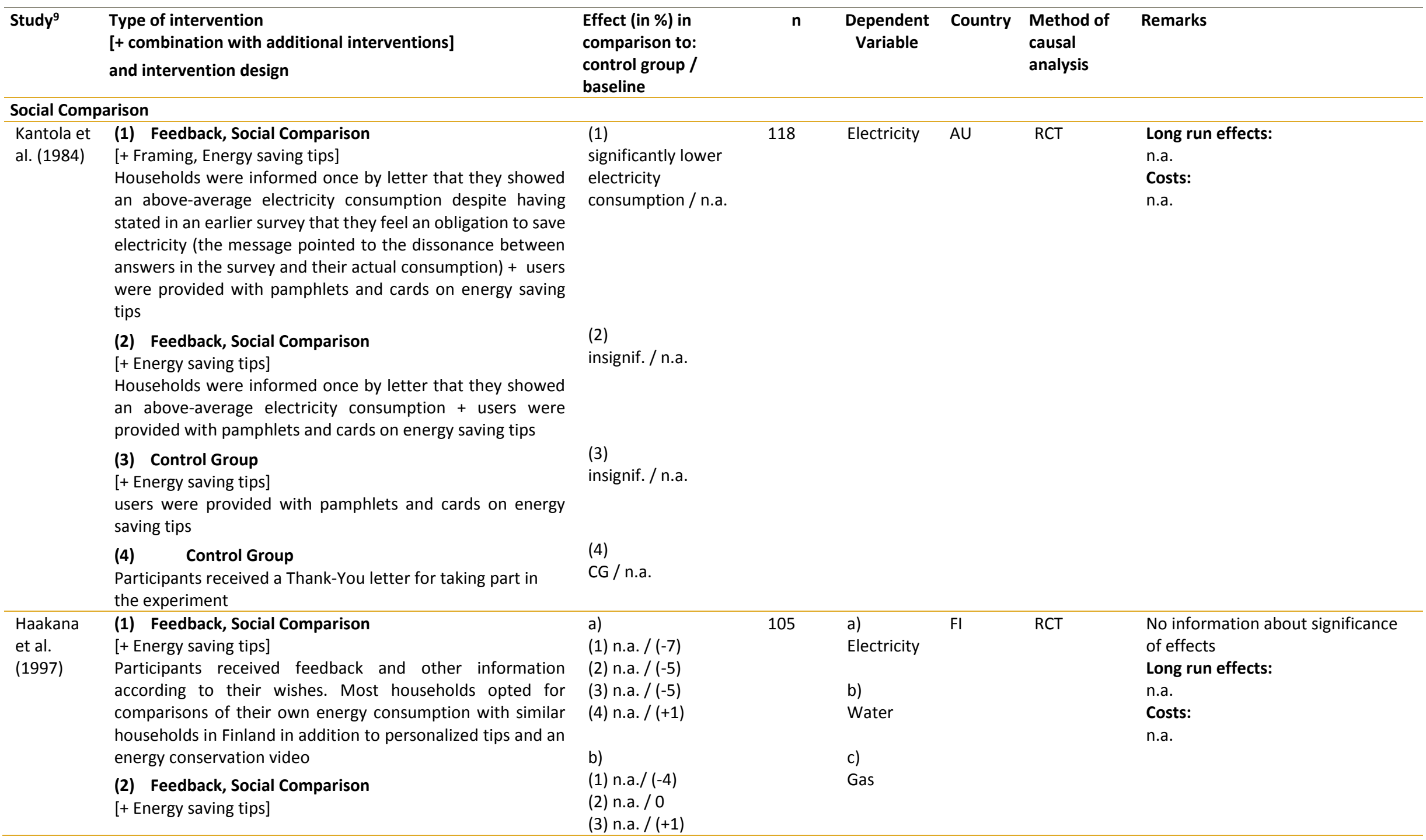

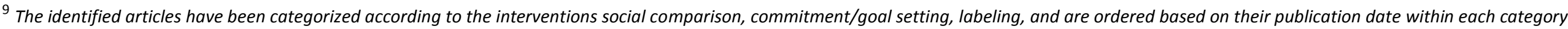
$n=$ sample size; $n . a .=$ not available; $C G=$ control group; ${ }^{* * *},{ }^{* *},{ }^{*}$ significance levels of $1 \%, 5 \%$ and $10 \%$, respectively.
} 
As in treatment (1) but with tailored information in written

\section{(4) n.a. / (+1)}

form instead of a video

\section{(3) Feedback, Social Comparison}

As in treatment (1), but without any tailored information or energy saving tips

c)

\section{(4) Control Group}

1) n.a. / (-9)

(2) n.a. / (-7)

(3) n.a. / (-4)

Participants of the Control Group didn't know they were part of an experiment

\section{(1) Feedback, Social Comparison}

[+ Energy saving tips]

Groups consisting of six to ten people met as "EcoTeams" once a month to discuss environmentally relevant behavior.

During the sessions they received feedback about their energy savings. Topics at the meetings were: garbage, gas, electricity, water, transport and consumer behavior.

\begin{tabular}{|c|c|c|c|c|c|}
\hline $\begin{array}{l}\text { (1) } \\
\text { n.a. / (-4.6) [insignif.] }\end{array}$ & 482 & $\begin{array}{l}\text { (1) } \\
\text { Electricity }\end{array}$ & $\mathrm{NL}$ & Diff-in-Diff & $\begin{array}{l}\text { Long run effects: } \\
\text { ( } 2 \text { years after stop of the EcoTeam- } \\
\text { meetings) }\end{array}$ \\
\hline (2) & & (2) & & & (1) $(-7.6)^{* *}$ \\
\hline n.a. $/(-20.5)^{* *}$ & & Gas & & & $\begin{array}{ll}\text { (2) } & (-16.9)^{* *} \\
\text { (3) } & (-6.7)^{* *}\end{array}$ \\
\hline (3) & & (3) & & & Costs: \\
\hline n.a. / (-2.8) [insignif.] & & Water & & & n.a. \\
\hline $\begin{array}{l}(1) \\
\text { n.a. / (-5.68)* }\end{array}$ & 287 & Electricity & US & RCT & 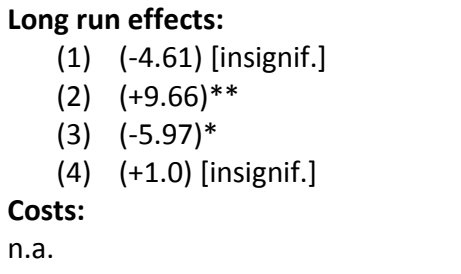 \\
\hline $\begin{array}{l}\text { (2) } \\
\text { n.a./ }(+8.57)^{*}\end{array}$ & & & & & \\
\hline $\begin{array}{l}\text { (3) } \\
\text { n.a./ }(-8.34)^{* *}\end{array}$ & & & & & \\
\hline $\begin{array}{l}\text { (4) } \\
\text { n.a./ (+2.32) } \\
\text { [insignif.] }\end{array}$ & & & & & \\
\hline
\end{tabular}


Same intervention as in (2) + happy face, because the households consumed less than average

Peschiera (1) Feedback

et al. [+ Comparison to usage history, Reminder]

\section{(1)}

Online-feedback about individual past and present electricity [insignif.]

consumption + three weekly reminders to check the onlinetool

\section{(2) Feedback, Social Comparison}

$\begin{array}{ll}\text { [+ Comparison to usage history, Reminder] } & (-6) \text { [insignif. } \\ \text { As in treatment (1) + comparison of the individual electricity } & \text { [insignif.] }\end{array}$

consumption with the average consumption of the rest of the

\section{building}

\section{(3) Feedback, Social Comparison}

[+ Comparison to usage history, Reminder]

(3)

As in treatment (2) + information about the electricity

consumption of "peers" (i.e. occupants of the building who in

a pre-survey the treated households classified as "known")

\section{(4) Control Group}

Participants knew they were part of an experiment

\section{Allcott (1) Feedback, Social Comparison}

(2011) [+ Comparison to usage history, Energy saving tips]

Monthly / bimonthly/ quarterly feedback via mail (Home

Energy Report with personal history of consumption,

comparison to neighbors and tips to save energy)

$$
(-21)^{* * *} /(-34)^{* * *}
$$

\section{(2) Control Group}

No information about participation in study

\section{CG/n.a.}

$$
\text { (1) }
$$$$
(-2,03)^{* * *} / \text { n.a }
$$

588446 Electricity

US

RCT

\section{ong run effects: \\ n.a.}

Costs: 


\section{(2) Feedback}

Ferraro and [+ Energy saving tips, Framing (social norm)]

Price Onetime personalized letter with heavily norm-based

(2013) language about saving water, feedback from the consumption bill, tips to save energy

\section{(3) Feedback, Social Comparison}

[+ Energy saving tips, Framing (social norm)]

Like (2) plus a comparison to the median water consumption

of the preceding summer and a classification of the household into one of the consumption groups
(4) Control Group

No information about participation in experiment

Peschiera (1) Feedback, Social Comparison

and Taylor [+ Comparison to usage history]

(2012) Participants get access to their electricity consumption data through an online-tool + information about consumption of the last seven days + a comparison with the average

residential electricity use + weekly reminders to check the online-tool

\section{(2) Feedback, Social Comparison}

\section{[+ Comparison to usage history]}

Same intervention as in (1) + data about the electricity use of

"peers" i.e. occupants of the building the treated households

mentioned to "know" in a pre-survey

\section{(3) Control Group}

Participants knew they were part of an experiment

Ayres et al. (1) Feedback, Social Comparison

(2013) [+ Energy saving tips, Comparison to usage history, Graphical enhancement]

Home Energy Reports (HER) about electricity consumption via mail, monthly for heavy users, quarterly for light users, with tips to save energy, personal history of consumption and

comparison to neighbors (additionally laughing or sad smiley, depending on consumption being below- or above-average)
$(-8.8)^{* *} /$ n.a.
(4)

$(-2,7)^{* * *} /(-10.08)$

CG / $(-7,83)$

(1)

0 [insignif.] / n.a.

88

Electricity US

$\mathrm{RCT}$

are calculated for above-

average users only. If below-average users are included in the sample, the effects turn insignificant.

Long run effects:

n.a.

Costs:

n.a.
(2) $(-0,22)$ (insign.)/ n.a.

Costs:

0,575 per saved 1000 gallons ( 785,41 Liter) of water
(3)

CG / n.a.

$(-2,02)^{* * *} /$ n.a.

$84000(1)+(2):$

Electricity

US

RCT

(3) Gas

\section{Long run effects:}

n.a.

(1) 4.94 Cents per kWh saved

(2) 1.78 Cents per kWh saved

(3) n.a. 


\section{(2) Feedback, Social Comparison}

[+ Energy saving tips, Comparison to usage history, Graphical $(-1,22)^{* * *} /$ n.a.

enhancement]

Like (1), the HER additionally contained information about the

gas consumption, frequency random (monthly/quarterly)

(3) Feedback, Social Comparison

[+ Energy saving tips, Comparison to usage history, Graphical $(-1,20)^{* * *} /$ n.a.

enhancement]

Like (2), gas consumption measured instead of electricity

consumption

\section{(4) Control Group}

No information about participation in experiment

Kahn [+ Energy saving tips, Comparison to usage history] Home Energy Reports (HER) about electricity consumption $\quad(-2,4)^{* * *} /$ n.a. via mail, monthly for heavy users, quarterly for light users, with tips to save energy, personal history of consumption and Conservatives: comparison to neighbors

\section{(2) Control Group}

$(-1,7)^{* * *} /$

No information about participation in experiment
Costa and (1) Feedback, Social Comparison

\section{Electricity US \\ US}

RCT intervention's heterogeneous effects ("Liberals" vs. "Conservatives"). The average treatment effect is

$(-2.1)^{* * *}$ compared to the control group.

Long run effects:

n.a.

Costs:

According to the authors, the intervention might be cost-effective, but no specific statement.

\section{Dolan and (1) Feedback, Social Comparison}

$$
\text { (1) }
$$

$(-4,4)^{* * *} /$ n.a

569 Gas

(2) Feedback, Social Comparison

[+ Energy saving tips]

Like (1) + Tips to save energy

(3) Control Group

Feedback about personal electricity consumption
(3)

CG / n.a.
Experiment 2 of the article fits

thematically and is generally suitable

to identify causal effects, but the

information in the working paper is contradictory and is therefore not

listed here.

Long run effects:

(18 months after first Intervention)

(1) $(-7,0)^{*}$ 


\section{Mizobuchi (1) Feedback}

and

[+ Financial Incentive, Comparison to usage history]

Takeuchi Monthly feedback via mail, reward of 200 Yen (2\$) for $1 \%$

(2013)

\section{(2) Feedback, Social Comparison}

[+ Financial Incentive, Comparison to usage history]

Monthly feedback via mail, comparison to other participating

households, reward of 200 Yen (2\$) for $1 \%$ reduction of

energy consumption

\section{(3) Control Group}

Information about participation in study

\section{Tiefenbeck (1) Feedback, Social Comparison}

et al. [+ Energy saving tips, Framing (social norm)]

(2013) Weekly feedback about the water consumption per capita

and tips to save water, partly complemented by a social

comparison with the $10 \%$ saving the most water or a social

appeal to contribute one's share to the mutual goal of energy

conservation

\section{(2) Control Group}

Information that water consumption will be monitored in the

course of a scientific study

CG / (-1,721)

$$
\text { (1) }
$$

Water:

$(-6,0)^{* *} /$ n.a.

Electricity:

$(+5,6)^{* *} /$ n.a.
Costs:

According to the authors $333 \mathrm{kWh}$ were saved for every Pound spent

Effects as difference from pretreatment-consumption. The difference between the effects of (1) and (2) is statistically not significant.

Long run effects:

n.a.

Costs:

n.a. 
Allcott and Monthly feedback via mail ( Home Energy Report with

Rogers personal history of consumption, comparison to neighbors

(2014) and tips to save energy)

\section{(2) Feedback, Social Comparison}

[+ Comparison to usage history, Energy saving tips]

Quarterly feedback via mail (Home Energy Report like in (1))

\section{(3) Control Group}

No information about participation in study

measurement of the effect after the shipping of four reports, the

treatment groups were randomly reallocated):

- Stop of the intervention after two years: $(-2)^{* * *}$

- Biannual receipt of Home Energy Reports : $(-3,1) * * *$

- Receipt of the Home Energy Reports in initial frequency: $(-3,3)^{* * *}$

\section{Costs:}

Costs of production and shipping of the reports divided by kWh of saved energy

- Assuming that the savings-

effect does not last:

3,2-4,44 Cents/kWh

- Assuming that the effects last

for the long term:

1,35 - 1,79 Cents/kWh

\section{Delmas and (1) Feedback, Social Comparison}

(1)

Lessem [+ Comparison to usage history, Reminder]

$(-5,68)$

66 Electricity US

RCT

Real-time feedback and comparison with other users through (insign.) / n.a.

an online-platform, weekly reminder via e-mail

(2) Feedback, Social Comparison

[+ Comparison to usage history, Reminder]

$(-19,36)^{* *} /$ n.a.

Additionally to (1) public rankings of which student rooms

consume below- or above-average (via posters in the

entrance hall and via e-mail)

(3) Control Group

(3)

No information about participation in experiment

\section{Komatsu (1) Feedback, Social Comparison}

and Nishio Onetime feedback via mail and comparison to median

(2015) consumption

CG / n.a.

(1)

No effect sizes given;
tendencies for

assessment of own

\section{Electricity}

(indirect)

$J P$

RCT

asse

the participants

(1) own electricity consumption in comparison to the neighbors' consumption was

Long run effects:

17 weeks after first intervention

(1) $(-6,5)$ (not sign.) / n.a.

(2) $(-24,76) * /$ n.a.

(3) n.a.

Costs:

n.a. 


\section{consumption}

\section{higher**}

\section{(2) Feedback, Social Comparison}

(2)

Like (1) plus comparison to highest saving $25 \%$ of participants higher ***

(3) Feedback, Social Comparison

[+ Framing (social norm)]

(3)

Like (2) plus a message about the social acceptance /

disapproval of own consumption

\section{(4) Feedback, Social Comparison}

Like (1)

(5) Feedback, Social Comparison

Like (2)

(6) Feedback, Social Comparison

[+ Framing (social norm)]

Like (3)

(7) Control Group

Simple feedback of electricity consumption

\section{Schultz et (1) Feedback}

al. (2015) [+ Energy saving tips]

Real-time feedback via IHD and provision of a „climate protection video"

(2) Feedback

[+ Energy saving tips]

Real-time feedback via IHD with the consumption being

converted to actual costs, video

(3) Feedback, Social Comparison

[+ Energy saving tips]

Real-time feedback via IHD and comparison to other

participants, video

(4) Control Group

Only video, no feedback

(1) Control Group

[+ Energy saving tips]
(2)

(insign.) / n.a.

(3)

$(-9,0)^{* *} /$ n.a. higher ***

(4)

Motivation to save

energy: insign.

(5)

insign.

(6)

higher $* * *$

(7)

n.a.

(1)

$(-3,0)$ (insign.) ) / n.a.

431 Electricity

US

$\mathrm{RCT}$

Long run effects: (three month after Intervention)

(1) $(-0,81)$ (not sign.)

(2) $(+1,13)$ (not sign.)

(3) $(-7,02)^{* *}$ analyzed, in (4)-(6) it was the

households' motivation to save

Costs:

n.a. CG / n.a.

(1)

CG / (+40,8) (insign.)
374 Water US

RCT

Consumption was measured on week after the intervention. 
Seyranian Onetime letter with tips to save energy

et al.

\section{(2) Feedback, Social Comparison}

Like (1) plus information about own personal consumption in

comparison to average consumption of neighborhood,

complemented by a laughing or sad smiley

\section{(3) Control Group}

[+ Energy saving tips, Framing (social norm)]

Like (1) plus a cover letter with the city logo, emphasizing the

household's role as a part of the community and stressing on

water conservation as a mutual goal

\section{(4) Control Group}

[+ Energy saving tips, Framing (personal norm)]

Like (1) plus a cover letter, setting water conservation as a

goal, but accentuating the household as a single player and

not as a part of the community
Long run effects :

(four weeks after intervention)

(1) CG / +16.2 (insign.)

(2) $(-11,5)^{* *} /+2,6$ (insign.)

(3) $(-12,2) * * /+2,6$ (insign.)

(4) $(-12,1)^{* * *} /+3,5$ (insign.)

Costs:

(3)

$(-34,1)^{* *} /(+1,4)$

n.a.

$(-24,6)$ (insign.)/

$(+3,4)$ (insign.) 


\section{Commitment and Goal Setting}

\section{Becker (1) Goal Setting}

(1978)

\section{[+ Energy saving}

$(1)$
$(-1.3)$ [insignif.] / n.a.

100

Variable

causal

analysis

were asked to reduce their energy

consumption by $20 \%$ compared to their baseline usage +

they received energy conservation tips specific to their own household appliances

(2) Feedback, Goal Setting

[+ Energy saving tips]

Same intervention as in (1) + they received feedback

about their energy consumption three times a week

(3) Goal Setting

\section{[+ Energy saving tips]}

Participants were asked to reduce their energy

consumption by $2 \%$ compared to their baseline usage + they received energy conservation tips specific to their own household appliances

\section{(4) Feedback, Goal Setting}

[+ Energy saving tips]

Same intervention as in $(3)+$ they received feedback

about their energy consumption three times a week

(5) Control Group

Participants of the control group knew they were part of CG / n.a. an experiment

Winett et (1) $\begin{aligned} & \text { Feedback, Goal Setting } \\ & \text { al. (1979) }\end{aligned}$
$\quad$ Enemparison to usage history, Graphical enhancement,
Eaily feedback sheet with information about electricity
usage + comparison with own usage on the preceeding
day + a happy or frowning smiley for a decrease or
increase in consumption + usage change compared to
baseline + feedback whether they achieved a goal, which
they had set themselves in a meeting before the start of
the experiment + energy conservation information

\section{Long run effects: \\ (1) (-11) (insign.) \\ (2) (-7) (insign.)}

Effects are calculated relative to the

mean consumption of the two

control groups

Costs:

Feedback condition:

- total expenditure per household $=\$ 26$ 


\section{(2) Feedback}

[+ Energy saving tips]

Households had to read and report their daily electricity

consumption + received energy saving information

(3) Control Group

Households agreed to participate in the study

(4) Control Group

Households denied to participate in the study
$(2)$

$(-7) * /$ n.a.

(3)

CG / n.a.

(4)

CG / n.a.

Dependent Country Method of Remarks

Variable causal

analysis

\section{Winett et Study 1 (during winter): \\ al. (1982) (1) Feedback, Goal Setting \\ [+ Energy saving tips] \\ Participants took part in a meeting and received information about energy conservation + they had to sign a commitment to reduce their energy consumption by $15 \%$ within the next 35 days + they received written feedback about their energy use + they were provided with a tape which presented information on energy conservation in form of a discussion}

\section{(2) Goal Setting}

[+Energy saving tips]

Participants took part in a meeting and received information about energy conservation + they had to sign a commitment to reduce their energy consumption by $15 \%$ within the next 35 days + they received a video which presented model homes similar to the participants homes and explained possible ways to reduce energy consumption.

(3) Feedback, Goal Setting [+ Energy saving tips] As in treatment (2) + feedback

\section{(4) Goal-Setting}

[+ Energy saving tips]
(2)

$$
\text { n.a. / (-11)*** }
$$

n.a. / (-14)***

n.a. / (-1) (insign.)

.
Savings per household $\$ 44$ from expected expenditures based

on the comparison group's use during this same period and the marginal cost per KWH. self-monitoring:

- $\quad$ total expenditure per household: \$22

- $\quad$ Savings per household: \$26 n.a. $/(-13)^{* * *}$

83 Electricity US

RCT

Long run effects: $n . a$.

Costs: n.a. 
As in treatment (1) but without feedback

(5) Control Group

Participants of the control group knew they were part of CG / (+4)

an experiment

Study 2 (during summer):

(6) Feedback, Goal Setting

As in treatment (3) but without information on energy n.a./(-19)*** conservation

(7) Feedback, Goal Setting

[ + Energy saving tips]

As in treatment (1) but without discussion tape

(8) Goal Setting

[ + Energy saving tips]

n.a. $/(-22)^{* * *}$

As in treatment (2)

(9) Control Group

Participants of the control group knew they were part of CG / (-2) an experiment

\begin{tabular}{|c|c|c|c|c|c|c|c|c|}
\hline $\begin{array}{l}\text { Katzev and } \\
\text { Johnson } \\
(1983)\end{array}$ & (2) & $\begin{array}{l}\text { Goal Setting } \\
\text { "Foot-in-the-door-treatment": Households were asked to } \\
\text { fill in an energy conservation questionnaire. Afterwards, } \\
\text { they were told to reduce their electricity consumption by } \\
10 \% \text { within the next two weeks } \\
\text { Goal Setting } \\
\text { Households were asked to reduce their electricity } \\
\text { consumption by } 10 \% \text { within the next two weeks } \\
\text { Control Group }\end{array}$ & $\begin{array}{l}\text { (1) } \\
\text { n.a. / (+11) [insignif.] } \\
(2) \\
\text { n.a. / (+12) [insignif.] }\end{array}$ & 66 & Electricity & US & RCT & $\begin{array}{l}\text { The subjects were recruited through } \\
\text { a door-to-door solicitation } \\
\text { procedure in which they were asked } \\
\text { for permission to read their } \\
\text { electricity meters as part of a study } \\
\text { on residential energy consumption. } \\
\text { Long run effects: } \\
\quad(+1)^{* *} \\
(-2)^{* * *} \\
(-5)^{* *} \\
(+5) \\
\text { (all effects compared to baseline } \\
\text { period; significance compared to } \\
\text { control group) } \\
\text { Costs: } \text { n.a. }\end{array}$ \\
\hline
\end{tabular}


and intervention design

Katzev and (1) Goalse

Johnson

\section{1) Goal Setting}

(1)

(1984) [+ Energy saving tips]

(-6.1) [insignif.] / (-

90 Electricity US

causal

analysis

consumption by $15 \%$ within the next two weeks +

received a utility guide for household energy conservation

(2) Goal Setting

(2)

Households were asked to reduce their energy (+1.4) [insignif.] / (-

consumption by $15 \%$ within the next two weeks + had to 5.9$)$ [insignif.]

fill in an energy conservation survey

(3) Control Group

[+ Financial incentive, Energy saving tips]

(+2.0) [insignif.] / (-

Households received a financial reward depending on the 5.3) [insignif.]

amount of electricity saved + a utility guide for household energy conservation

(4) Goal Setting

[+ Financial incentive, Energy saving tips] (-3.7) [insignif.] / (-

Households received a combination of the interventions in 11.0) [insignif.]

(2) and (3)

(5) Control Group

Households were asked to fill in a short energy (+7.5) [insignif.]/

conservation survey

+0.2 ) [insignif.]

(6) Control Group

(6)

Households agreed to have their electricity meters read by CG / (-7.3) [insignif.] the experimenters

van

(1) Feedback, Goal Setting

(1)

[+ Energy saving tips]

n.a. $/(-12,3)^{* * *}$

325

Gas

$\mathrm{NL}$

$\mathrm{RCT}^{10}$

Long run effects : (one year after

SmartMeter and IHDs were installed and households

$\mathrm{n}$ and van

were asked to monthly jot down their preferred and

actual consumption of gas. Externally imposed goal: 10\%

consumption reduction in comparison to preceding year.

Additionally tips to save energy.

(2) Feedback

[+ Energy saving tips]

n.a. $/(-7,7)^{* * *}$

Long run effects:

(1) $(-2.8) /(-14.3)$

(2) $(-1.3) /(-12.8)$

(3) $(+0.2) /(-11.3)$

(4) $(-10.7) /(-22.2)$

(5) $(-1.5) /(-13.0)$

(6) CG / (-11.5)

All effects are insignif.

Costs: n.a.

${ }^{10}$ The description of the study suggests an experimental design such as an RCT, even though the random assignment (to control and experimental groups) is not explicitly mentioned. 
Monthly feedback (not stated through which canal) and tips to save energy

Costs:

(3) Feedback

[+ Energy saving tips]

Households were asked to document their monthly gas

consumption on observation sheets, additionally tips to save energy

(4) Control Group

[+ Energy saving tips]

Provision of tips to save energy

(5) Control Group

No information about participation in experiment

(6) Control Group

Contacted households did not want to participate in the experiment

McCalley Laboratory study, in which the participants had to set up

and washing machines on a computer: the first six washing cycles

Midden for an evaluation of the "base consumption", which the

(2002) participants received feedback about. The following

interventions were randomly assigned, afterwards another 20

n.a. $/(-4,3)^{* *}$

(5)

n.a. / (-0,3) (insign.)

(6)

CG / (-0,2) (insign.)

\begin{abstract}
washing cycles.
\end{abstract}
(1) Control Group

No Feedback, no goal

CG / no difference to

(2) Feedback

Feedback, no goal

(2)

(3) Feedback, Goal Setting, Commitment

n.a. / (-9,6) (insign.)

$(3)$

Feedback, self-imposed goal (Options: $0 \%, 5 \%, 10 \%,\left(-12,3^{* * *}\right) /(-21,9)^{* * *}$ $15 \%, 20 \%)$

(4) Feedback, Goal Setting

Feedback, externally imposed goal (20\%)
Abrahamse
(1) Feedback, Goal Setting
(1) + (2)
Externally set goal of energy conservation (5\%), online significant difference feedback about personal consumption after two and five
et al. months

189 Electricity, NL $\quad$ RCT
Gas

$\begin{array}{ll}\text { Laboratory Long run effects : } & \\ \text { Experiment } & \text { n.a. } \\ & \text { Costs: }\end{array}$

n.a. fects refer to direct energy

consumption, not to the as well

measured indirect consumption, because the indirect consumption 
and intervention design

\section{(2) Feedback, Goal Setting} [+ Framing (social norm)]

to control group $* * *$ (and

Like (1) plus a mutual goal (all together saving 5\%) and

online feedback about the group's consumption after two and five months

(3) Control Group

Twice filling out a questionnaire, no other intervention

strongly varied and was not seen as robust by the authors. For the analysis of the direct energy consumption both treatment groups were taken together, as there were no significant differences between them.

Long run effects :

n.a.

Costs:

n.a.

\section{Harding Offer for customers to participate in program to save}

and Hsiaw electricity. Range of goals to set for oneself between 0\%, 0-

(2014) $\quad 15 \%, 15-50 \%$, over $50 \%$

(1) Feedback, Goal Setting, Commitment

[+ Comparison to usage history]

Self-set goal: $0 \%$, daily access to website with monthly

bills of consumption

(2) Feedback, Goal Setting, Commitment

[+ Comparison to usage history]

Self-set goal : 0 - 15\%, daily access to website with monthly bills of consumption

(3) Feedback, Goal Setting, Commitment

[+ Comparison to usage history]

Self-set goal : $15-50 \%$, daily access to website with

monthly bills of consumption

(4) Feedback, Goal Setting, Commitment

[+ Comparison to usage history]

Self-set goal : über $50 \%$, daily access to website with

monthly bills of consumption

(5) Control Group

No information about participation in experiment

(1)

$(-1,5)$ (not sign.) / n.a.

(2)

$(-11,0)^{* *} /$ n.a.

$(-1,0)$ (not sign.) / n.a.

(4)

$0 /$ n.a.

(5)
CG / n.a.
12451 Electricity US Matching

Households with optimistic goals (15-50\%) save quite a lot shortly after start of the program. This effect wanes after two to three months, presumably because the consumers realized that they would not be able to reach their very optimistic goals.

Long run effects ( after 18 months) for (2):

Significant effects with significance level of $95 \%$; no specific statements about size Costs: 
and intervention design

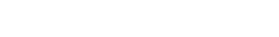

(1) Control Group

(2) Labeling

[+ graphical enhancement]

Verplanken

and

Weenig

(1993)

\section{in local currency), no time pressure}

(3) Control Group

Information on consumption in $\mathrm{kWh}$, time pressure $(5$

minutes for decision)

(4) Labeling

[+ graphical enhancement]

Annual energy consumption as graphical label, time

pressure

Kurz et al. (1) Labeling

2005)

Labeling
A series of labels was placed on different appliances in the

a. / from insign. to (-

household: refrigerators, air conditioners, showers, 23)**

washing machines, clothes dryers, dishwashers, toilets

and outdoor taps. The labels provided information about

the water and energy-consumption levels of the labeled

appliances.

(2) Control Group

Households were provided with the same information as n.a. / insignif.

in treatment (1) but in the form of information leaflets instead of labels

(3) Feedback, Social Comparison

[ + Graphical enhancement]

Households received e-mails with graphical feedback on

their levels of water and energy consumption and a comparison to other households of similar size who participated in the study
Brounen Labeling
and Kok Analysis of the effect of the EU label for energy efficiency on

(2011)

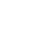

$(+3,7)^{* * *}$

$$
(+3,7)^{* * *}
$$

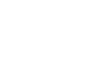

(2)

(indirect)

Effect = share of group that prefers an efficient refrigerator to an

with random

ssignment Long run effects :

to n.a.

experimental Costs:

groups

n.a.

$31993 \quad \begin{aligned} & \text { Electricity, } \\ & \text { water, gas } \\ & \text { (indirect) }\end{aligned}$

\begin{tabular}{|c|c|c|c|}
\hline $\begin{array}{l}\text { Electricity } \\
\text { and Water }\end{array}$ & $\mathrm{AU}$ & RCT & $\begin{array}{l}\text { The study reports the effects for } \\
\text { seven weeks separately, without } \\
\text { documenting an average treatment } \\
\text { effect. Therefore, we report the } \\
\text { interval of the documented effects. }\end{array}$ \\
\hline
\end{tabular}

Long run effects: $n$.a.

Costs: n.a. 
(1) Labeling

Consumption information in Watt and current price for

electricity

Consumption information in Watt

(2)

(3) Labeling

Actual annual operating costs of the devices

Experiment 2:

Choice between two TVs with differing information:
(4) Control Group
(4)
Consumption information in Watt (60 Watt vs. 225 Watt) 481,22

(5) Labeling

Absolute operating costs for the course of ten years

$641,96 * *$ (180€ vs. $660 €)$

(6) Labeling Annual operating costs (18€/year vs. 66€/year) (sificant difference

to the other

treatment groups)

\section{Dependent Country Method of Remarks \\ Variable \\ causal \\ analysis}

with two-

step

Costs:

Heckman-

procedure

Choice-

$\begin{array}{lll}\text { Electricity DE } & \text { Choice- } \\ \text { (indirect) } & & \text { Experiments }\end{array}$

(indirect) Experiments

with random

assignment Effects (1)-(3) =

to

Proportion of participants who

experimental correctly estimate the energy saving

groups potential in \% / who overestimate /

within who underestimate
Effects (4)-(6) =

Median willingness to pay for a more efficient TV in Euro (actual saving potential: 480 Euro).

\section{Long run effects:}

n.a.

Costs:

n.a.

$\begin{array}{lll}\begin{array}{l}\text { Electricity US } \\ \text { (indirekt) }\end{array} & \begin{array}{l}\text { Two natural } \\ \text { experiments }\end{array} & \text { Effects }(1)+(2)= \\ & & \text { Everage willingness to pay for the } \\ & \text { price for refrigerator in } \%\end{array}$

\section{Houde \\ atural Experiment 1 :}

(2014)

(1) Labeling

The tightening of the criteria for the receipt of the

(1)

Energy Star Label in 2008 in the US allowed to observe

the willingness to pay for the same models of

$(+19)^{* *} / 1,5$


control group /

baseline

refrigerators in the same store with and without the label (before and after the change of regulation) Natural Experiment 2:

(2) Labeling

In January 2010 it was published that some refrigerators received the Energy Star Label, although they did not actually fulfil the criteria (incorrect appliance of the test procedure). Because the following withdrawal of the

label could not be anticipated by either the producers or the customers, the label's value can be determined by the willingness to pay for these models of refrigerators before and after January 2010.
$(+89,6)$ (insign.) / 7,07 184645

\section{Dependent Country Method of Remarks \\ Variable \\ causal}

analysis
Newell and Survey (online) about six different hypothetical purchase

Siikamäki decisions for warm water processors. There are three boilers

(2014) to choose from. The boilers differ in price and each boiler is

labelled with a different version of the Energy Star Label,

which differ in the kind of information that is provided:

(1) Labeling

Only the simple consumption information is provided

(2) Labeling

Like (1) + relative consumption costs in comparison to different devices

(3) Labeling

Like (2) + Information about the $\mathrm{CO} 2$ emissions

(4) Labeling

Like (2) + specific information on energy consumption

(5) Labeling

[+ graphical enhancement]

Wie (4) + awarded with an „Energy-Star-Label“

(6) Labeling

[+ graphical enhancement]

\section{Long run effects:}

n.a.

Costs:

The opportunity costs of imperfect information amount to about $\$ 15$ per refrigerator sold. Extrapolated on the whole market for

refrigerators that makes a sum of

$\$ 135 \mathrm{mil} /$ year. According to the

author that is twice as much as

the annual costs for the Energy

Star Label program.
(2)

$0,68^{* *}$

(3)

0,93 (insign.)

(4)

1,02 (insign.)

(5)

$1,36 * *$

(6) $\begin{aligned} & 1184 \text { Electricity } \\ & \text { and gas } \\ & \text { (indirect) }\end{aligned}$

US

Choice-

Experiment relative willingness to pay for

with random

assignment

to

experimental

groups

tal char

re change in sales price and a

tower than

1 shows an underestimation of

savings through energy efficiency,

while a value greater than 1 shows

an overestimation. The significance

is measured as the difference to 1 .

\section{Long run effects:}

n.a.

Costs:

n.a. 
Like (1) + Information about energy consumption in

relation to other devices in overseeable nuances (A-G ranking: „EU-Style“)

Ölander Choice between four TV devices with different labels;

and question which device the customer would buy

Thøgersen (1) Labeling

(2014) Labels with energy efficiency grades from A - G

(2) Labeling

Labels with energy efficiency grades from A+++ - D

\section{(1) $+(2)$}

The scale from $A-G$

more than doubled

the probability to

choose an energy-

efficient device in

comparison to the

scale from $\mathrm{A}+++$ - D

\section{Allcott and Experiment 1:}

Taubinsky Choice between an energy-saving bulb and three

(2015) conventional bulbs with comparable power.

\section{(1) Labeling}

Information about consumption, cost saving with energy- $(+2,30)^{* * *} / \mathrm{n}$.

saving bulbs, downsides of energy-saving bulbs (+

Information like in (2))

(2) Control Group

Information about amount of energy-saving bulbs sold

and sales development in the past.

\section{Experiment 2}

Customers in a big electrical store were asked about their

consumption behavior and with their individual information a

comparison of the energy consumption of energy-saving bulbs

and conventional bulbs was provided via Ipad:

\section{(3) Labeling}

[+ Financial incentive]

Annual and total energy costs + discount coupon

( $10 \%$ on all bulbs)

\section{Experiment}

Artificial

field

experiment": Effects (1) =

Choice -

Experiment

with random

assignment

experimental

groups. One

of 30 choices

(randomly

selected)

leads to

actual buying

decision.

$\begin{array}{ll}(3) & \text { (3)-(6) } \\ (-2,2) \text { (insign.) } & 1087\end{array}$

Experime

2: RCT
For experiment 1 several treatment

groups were summarized for the

analysis.

Willingness to pay in Dollar for an energy-saving bulb in comparison

to a conventional bulb and in comparison to the control group (2)

Effects (3)-(6) =

Probability of the purchase of an energy-saving bulb in comparison to conventional bulbs after the 
and intervention design

baseline

(4) Labeling

[+ Financial incentive]

Annual and total energy costs + discount coupon ( $10 \%$ on

all bulbs, $30 \%$ on energy-saving bulbs)

(5) Control Group

[+ Financial incentive]

$(+11,0)$ (insign.)

No interview/information, discount coupon ( $10 \%$ on al

bulbs, $30 \%$ on energy-saving bulbs)

(6) Control Group

[+ Financial incentive]

(5)

$+(7,8)^{*}$

No interview/information, discount coupon $(10 \%$ on all bulbs)

\section{Waechter Experiment 1:}

et al. On the basis of a scale from 0 (not efficient) to 100 (very

(2015) efficient) the participants had to estimate the energy consumption of a TV. Four different versions of a label (randomly assigned) provided information on the grade of energy efficiency ( $\mathrm{A}$ - high, $\mathrm{B}-$ low) and the electricit consumption (high, low).

\section{(1) Labeling}

Information about the grade of energy efficiency of the TV devices

\section{(2) Control Group}

Information about the electricity consumption of the TV devices

Experiment 2:

On the basis of two devices with different labels, participants had to decide which device they would recommend to an

(6) $38 \%$
CG; Probability for

energy-saving bulb

\section{Experiment 1:}

(1)

The higher the grade

of energy efficiency,

the lower the

estimates for the

electricity

consumption

(significant***)

(2)

No effect on estimates

of electricity

consumption information treatment and in comparison to the control group in percentage points.

\section{Long run effects:}

n.a.

Costs:

n.a.

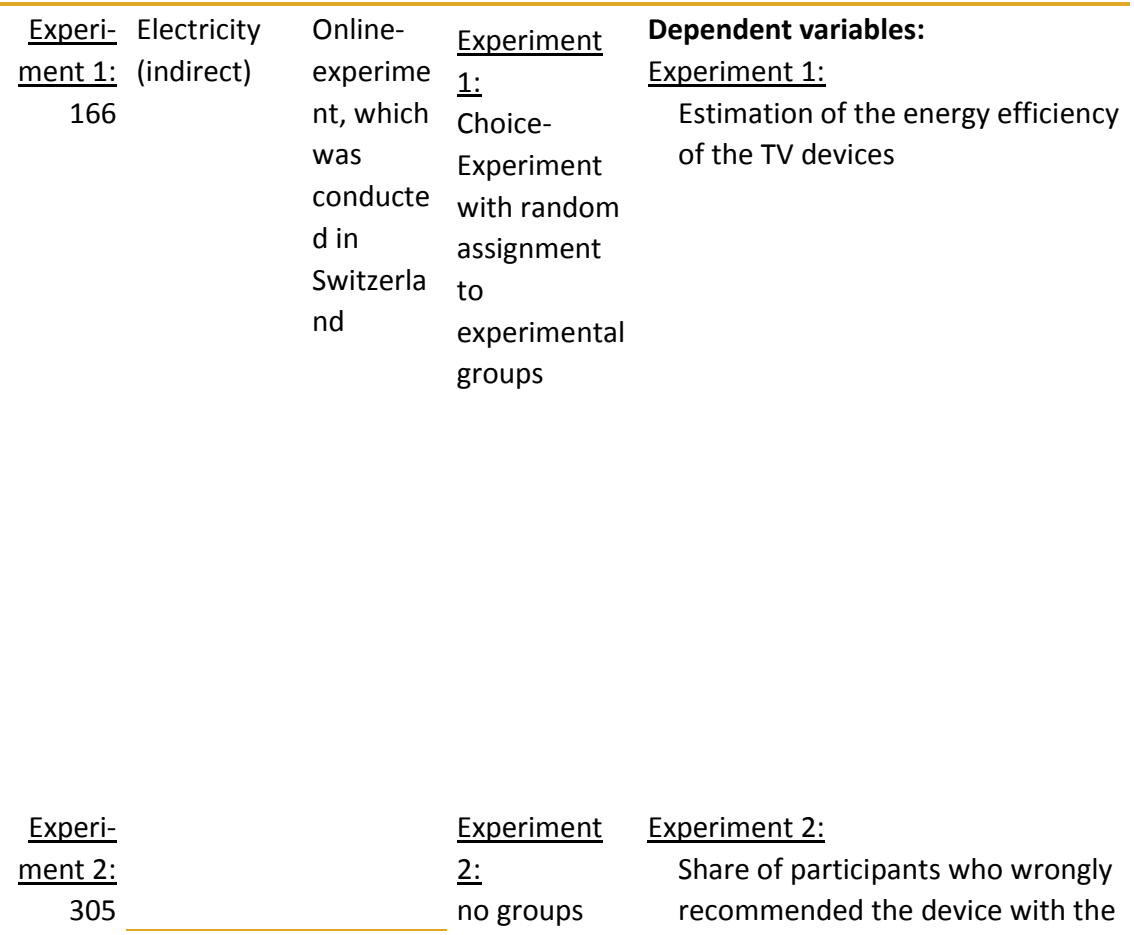

\section{Experi- \\ ment 2:}

305

Experiment 2:

Share of participants who wrongly recommended the device with the

no groups 
energy conserving person. The device with the higher grade of energy efficiency thereby featured the higher actual energy consumption.
(1) Labeling
Device $=$ TV
(2) Labeling
Device $=$ Freezer
Experiment 3:
(1)
(2)
72.8

On the basis of two different labels participants had to

evaluate the energy consumption of a freezer in comparison

to a reference refrigerator, whereas the labels differed only in

the grade of energy efficiency, but not in actual energy

consumption.

\section{(1) Labeling}

Label: „Grade of energy efficiency: A+++"

(2) Control Group

"Grade of energy efficiency: A+"
(1) $67.72 * *$

Experi-

ment 3:

(2) 77.07 (CG) higher actual energy consumption in $\%$

\begin{tabular}{|c|c|}
\hline Experiment & Experiment 3: \\
\hline 3: & Estimation of the energy \\
\hline Choice- & consumption of the freezer \\
\hline Experiment & compared to the reference \\
\hline with random & refrigerator on a scale from 1 to \\
\hline assignment & 100 \\
\hline to & Long run effects: \\
\hline experimental & n.a. \\
\hline groups & Costs: \\
\hline
\end{tabular}




\section{Appendix B (Intended for online publication):}

The keyword search in EconLit comprised the categories "Title", "Abstract", and "Subjects (SU)" for both journal articles and working papers. In ScienceDirect, we searched with keywords in the category "Abstract, Title, Keywords" and included articles from the disciplines "Economics, Econometrics, Finance",

"Psychology", "Social Sciences", “Environment", and "Energy".

Table B1: „List of Keywords“

\begin{tabular}{|c|c|}
\hline Intervention & Keywords \\
\hline \multirow[t]{8}{*}{ Social Comparison } & $\begin{array}{l}\text { "social norms" OR "social learning" OR "social modeling" OR "social influence" OR "peer } \\
\text { comparison" OR "peer information" OR "comparative energy information" OR "feedback" }\end{array}$ \\
\hline & AND \\
\hline & "energy conservation" OR "energy consumption" OR "energy use" OR "energy usage" OR \\
\hline & "energy demand*" OR "energy saving" OR "electricity conservation" OR "electricity \\
\hline & consumption" OR "electricity use" OR "electricity usage" OR "electricity demand*" OR \\
\hline & "electricity saving" OR "gas conservation" OR "gas consumption" OR "gas use" OR "gas usage" \\
\hline & OR "gas demand*" OR "gas saving" OR "water conservation" OR "water consumption" OR \\
\hline & $\begin{array}{l}\text { "water use" OR "water usage" OR "water demand*" OR "water saving" OR "conservation } \\
\text { behavior" }\end{array}$ \\
\hline \multirow[t]{9}{*}{ Commitment } & "pre-commitment" OR "precommitment" OR "pledge" OR "behavioral contract" OR \\
\hline & $\begin{array}{l}\text { "commitment contract" OR "commitment devices" OR "commitment approach*" OR "personal } \\
\text { commitment" OR "public commitment" OR "self-control" OR "self-regulation" }\end{array}$ \\
\hline & AND \\
\hline & "energy conservation" OR "energy consumption" OR "energy use" OR "energy usage" OR \\
\hline & "energy demand*" OR "energy saving" OR "electricity conservation" OR "electricity \\
\hline & consumption" OR “electricity use" OR "electricity usage" OR "electricity demand*" OR \\
\hline & "electricity saving" OR “gas conservation" OR "gas consumption" OR "gas use" OR "gas usage" \\
\hline & OR "gas demand*” OR "gas saving" OR "water conservation" OR "water consumption" OR \\
\hline & $\begin{array}{l}\text { "water use" OR "water usage" OR "water demand*" OR "water saving" OR "conservation } \\
\text { behavior" }\end{array}$ \\
\hline \multirow[t]{8}{*}{ Goal-Setting } & "goal setting" \\
\hline & AND \\
\hline & "energy conservation" OR "energy consumption" OR "energy use" OR "energy usage" OR \\
\hline & "energy demand*" OR "energy saving" OR "electricity conservation" OR "electricity \\
\hline & consumption" OR "electricity use" OR "electricity usage" OR "electricity demand*" OR \\
\hline & "electricity saving" OR "gas conservation" OR "gas consumption" OR "gas use" OR "gas usage" \\
\hline & OR "gas demand*" OR "gas saving" OR "water conservation" OR “water consumption" OR \\
\hline & $\begin{array}{l}\text { "water use" OR “water usage" OR “water demand*” OR "water saving" OR "conservation } \\
\text { behavior" }\end{array}$ \\
\hline \multirow[t]{9}{*}{ Labeling } & "energy labeling" OR "energy labelling" OR "information label*" OR "energy information" OR \\
\hline & $\begin{array}{l}\text { "energy label" OR "information acquisition" OR "information disclosure" OR "environmental } \\
\text { certification" }\end{array}$ \\
\hline & AND \\
\hline & "energy conservation" OR "energy consumption" OR "energy use" OR "energy usage" OR \\
\hline & "energy demand*" OR "energy saving" OR "electricity conservation" OR "electricity \\
\hline & consumption" OR "electricity use" OR "electricity usage" OR "electricity demand*" OR \\
\hline & "electricity saving" OR "gas conservation" OR "gas consumption" OR "gas use" OR "gas usage" \\
\hline & OR "gas demand*" OR "gas saving" OR "water conservation" OR "water consumption" OR \\
\hline & $\begin{array}{l}\text { "water use" OR “water usage" OR "water demand*" OR "water saving" OR "conservation } \\
\text { behavior" }\end{array}$ \\
\hline
\end{tabular}


Analysis refers to this standardized inclusion decision form in Citavi. If one of the criteria was coded with "no", the study was excluded from the systematic review.

Table B2: „Inclusion Decision Form“

\begin{tabular}{|l|l|}
\hline Author (year) & Text \\
\hline Title & Text \\
\hline Name of coder & Text \\
\hline $\begin{array}{l}\text { Study includes applied research (not just theoretical } \\
\text { models) }\end{array}$ & Options: yes / no / discuss \\
\hline Study includes at least one of the chosen interventions & $\begin{array}{l}\text { Options: Feedback / Social Comparison / Commitment } \\
\text { / Goal-Setting / Labeling / discuss }\end{array}$ \\
\hline Study refers to at least one of the outcome variables & Options: gas / water / electricity / discuss \\
\hline $\begin{array}{l}\text { Study targets private households or individuals in } \\
\text { private households }\end{array}$ & Options: yes / no / discuss \\
\hline Study was carried out in a developed country & Options: yes / no / discuss \\
\hline Inclusion decision & $\begin{array}{l}\text { Options: include / exclude / relevant meta-study / } \\
\text { discuss }\end{array}$ \\
\hline
\end{tabular}


Table B3: "Coding Sheet"

\begin{tabular}{|c|c|c|}
\hline Study & Authors (year) & Text \\
\hline Type of intervention & $\begin{array}{ll}\text { e.g. } \\
\text { (1) } 1 \\
\text { (2) } 1+2 \\
\text { (3) } 1+2+4 \\
\text { (4) } 0\end{array}$ & $\begin{array}{l}\text { Open code } \\
0=\text { Control group } \\
1=\text { Feedback } \\
2=\text { Social comparison } \\
3=\text { Commitment } \\
4=\text { Goal-setting } \\
5=\text { Labeling } \\
1+2=\text { Feedb. }+ \text { Social Comparison } \\
3+4=\text { Commitment }+ \text { Goal-Setting }\end{array}$ \\
\hline Intervention design & $\begin{array}{l}\text { e.g. } \\
\text { (1) Onetime letter, external goal } \\
\text { (5\%) } \\
\text { (2) Onetime letter, self-set goal } \\
\text { (3) Onetime letter, external goal, } \\
\text { comparison with another } \\
\text { treatment group }\end{array}$ & Text \\
\hline $\begin{array}{l}\text { Combination with additional } \\
\text { interventions }\end{array}$ & $\begin{array}{l}\text { e.g. } \\
\text { (1) None } \\
\text { (2) Energy saving tips } \\
\text { (3) None }\end{array}$ & Text \\
\hline $\begin{array}{l}\text { Effect (in \%) in comparison to: } \\
\text { control group / baseline } \\
\text { Significance level: } \\
* * *: p<0,01 \\
* *: p<0,05 \\
*: p<0.10 \\
\text { (insign.): not significant }\end{array}$ & $\begin{array}{l}\text { e.g. } \\
\text { (1) }(-2,2)^{* *} /(-5,4)^{* *} \\
\text { (2) }(-2,7)^{*} /(-10,0)^{*} \\
\text { (3) }(-0.5) \text { (insignif.) } /(-1,9)^{*} \\
\text { (4) } K G /(-1,1) \text { (insignif.) }\end{array}$ & Number \\
\hline $\mathbf{N}$ & $\begin{array}{l}e . g . \\
34000\end{array}$ & Number \\
\hline Dependent variable & $\begin{array}{l}\text { e.g. } \\
2\end{array}$ & $\begin{array}{l}\text { Open Code } \\
1=\text { Electricity } \\
2 \text { = Water } \\
3=\text { Gas } \\
\text { For Labeling: } \\
1 A=\text { Electricity (indirectly) } \\
2 A=\text { Water (indirectly) } \\
3 A=\text { Gas (indirectly) }\end{array}$ \\
\hline Country & $\begin{array}{l}\text { e.g. } \\
\text { US }\end{array}$ & Country code \\
\hline Method of causal analysis & $\begin{array}{l}\text { e.g. } \\
1\end{array}$ & $\begin{array}{l}\text { Open code } \\
1=\text { RCT } \\
2=\text { Matched Comparison } \\
3=\text { RDD } \\
4=\text { Diff-in-Diff } \\
5=\text { FE } \\
6=\text { Other }\end{array}$ \\
\hline Remarks & $\begin{array}{l}\text { e.g. } \\
\text { (1) Limitations } \\
\text { (2) Cost-benefit-analysis } \\
\text { (3) Long run effect + follow-up } \\
\text { period after intervention }\end{array}$ & Text \\
\hline
\end{tabular}




